The decentralization of Social Assistance and the rise of Disability Insurance enrolment

Gijs Roelofs

Daniel van Vuuren 



\title{
The decentralization of Social Assistance and the rise of Disability Insurance enrolment ${ }^{1}$
}

\author{
Gijs Roelofs \\ CPB \\ Daniel van Vuuren \\ CPB \& Netspar
}

\begin{abstract}
Many economists and policymakers believe that fiscal decentralization, the decentralization of government expenditures to local governments, enhances public sector efficiency. Vertical externalities - i.e. spillovers between local and central government - may however undo part of this advantage. In this paper, we assess spillover effects of Social Assistance (SA) decentralization in the Netherlands, in particular towards (a centrally administered) Disability Insurance scheme (DI). DI enrolment strongly increased since the decentralization of SA. We find that the sensitivity of local DI enrolment with respect to the stock of local SA recipients has increased over time, given that we control for both observed and unobserved disability risk factors. IV estimates show that, since the decentralization of SA, at least one third of DI inflow was diverted from SA.
\end{abstract}

Keywords: fiscal decentralization, vertical externalities, social assistance, disability insurance JEL code: H4O; H53; H7O

\begin{abstract}
Dutch
Veel economen en beleidsmakers geloven dat decentralisering van taken naar lagere overheden leidt tot efficiëntere besteding van overheidsgelden. Verticale externaliteiten - dat wil zeggen afwentelingsgedrag tussen verschillende overheidslagen - kunnen de efficiencywinst echter (deels) tenietdoen. In deze studie gaan we na of bij de decentralisering van de bijstand naar gemeenten sprake is geweest van afwentelingsgedrag naar de Wajong. De instroom in de Wajong is in de periode na de decentralisering van de bijstand immers steeds verder toegenomen. Uit deze analyse blijkt dat deze instroom steeds gevoeliger is geworden voor het aantal bijstandsgerechtigden, wat erop duidt dat gemeenten een prikkel ervaren om bijstandsgerechtigden richting de Wajong te dirigeren. Modelschattingen laten zien dat minimaal een derde van de instroom in de Wajong sinds 2004 het resultaat is geweest van afwenteling vanuit de bijstand.
\end{abstract}

Steekwoorden: decentralisering, verticale externaliteiten, bijstand, Wajong

\footnotetext{
${ }^{1}$ The authors thank Rob Alessie, Frits Bos, Wolter Hassink, Pierre Koning, Coen Teulings, Wouter Vermeulen, and Bas ter Weel for helpful discussions, and Peter Dekker and Sijmen Duineveld for research assistance. We also thank APE, Statistics Netherlands (CBS), and UWV for providing the data.
} 


\section{Introduction}

The Dutch Social Assistance scheme (SA) was gradually decentralized from central government to municipalities during the early 21 st century. Over the same period, the inflow into the Disability Insurance scheme for individuals with no employment history (DI $)^{2}$ has more than doubled. By 2008 , a rapidly growing share of $1.7 \%$ of the Dutch population between the ages of 18 and 65 were receiving benefits from this scheme. The DI scheme is fully financed by the central government. There is a general perception that the reform of the SA scheme has contributed to the increased inflow into DI. Municipalities may have been tempted to redirect (potential) SA recipients to the DI scheme as a result of their increased financial responsibility for Social Assistance. A similar issue seems to play in the US, where states have an incentive to keep their welfare rolls low and push people towards the federally funded SSI scheme. ${ }^{3}$ The main purpose of this paper is to investigate whether the misalignment of the central government's and local governments' interests has indeed played a role in the increase of DI inflow.

Many economists and policymakers believe that fiscal decentralization, the decentralization of expenditure responsibilities to lower-level government, enhances public sector efficiency. The empirical literature on the effect of fiscal decentralization on government efficiency is however remarkably small. Adam et al. (2008) find a positive relationship between decentralization and public sector efficiency based on comparisons between 21 OECD countries over the period 1970-2000. In a specific study on education decentralization in Switzerland, Barankay and Lockwood (2007) also find a robust, positive effect (as measured by educational outcomes). On the other hand, Ahmad et al. (2008) find mixed empirical evidence for OECD countries. It is clear both from the (large) theoretical and the (small) empirical literature that, apart from its merits, decentralization may have some adverse effects as well. The existing empirical studies however typically estimate reduced-form models to determine the total effect of fiscal decentralization on public sector efficiency. Specific (positive or negative) aspects of fiscal decentralization have not been assessed separately. In this paper, we empirically assess the importance of one particular aspect of fiscal decentralization, namely the magnitude of a vertical externality triggered by the decentralization of Social Assistance. To the authors' knowledge, this is the first empirical study trying to quantitatively assess the importance of externalities between local and central government.

An important virtue of fiscal decentralization is that local governments may be given an incentive to minimize costs. ${ }^{4}$ If the local government bears political responsibility, then voters will use the performance of comparable local governments as a benchmark for the performance of theirs (Besley and Smart, 2007). In addition, the central government may benchmark performances in order to efficiently allocate funds to local governments (Shleifer, 1985). Empirical evidence indeed points at yardstick competition enhancing the efficiency of local governments (Besley and Case, 1995). A second advantage of decentralization is that the electoral control over the provision of public services may increase (Seabright, 1996). Finally, lower-level governments are better able to adjust policy to local preferences, which may be welfare-enhancing (Cremer et al., 1996).

On the other hand, a well-known drawback of decentralization is that the costs of production may increase as a result of economies of scale. The production of some public services involves an important fixed cost component, and is therefore efficiently organized at a large scale. In practice, the problem of scale

\footnotetext{
${ }^{2}$ The Dutch acronym for this scheme is 'WAJONG', which translates as Disability Insurance scheme for the young and is simply referred to as DI throughout this paper.

${ }^{3}$ See The Economist of March 12, 2011 (pp. 48-49).

${ }^{4}$ For a more elaborate discussion on the pros and cons of fiscal decentralization, see Bos (2010).
} 
economies can however be resolved by separating provision from production through outsourcing,

subcontracting, or a proper division of responsibilities between the central and local government (Ahmad et al., 2008; Dafflon, 2008; Boadway and Shah, 2009). An example is a decentralized education system where local governments bear full operational responsibility, but where the central state is responsible for teacher training and quality controls. Economies of scope may also play a role. Separation of public services may increase total costs. For instance, if the unemployment insurance scheme is administered centrally and a scheme for the longterm unemployed (e.g., Social Assistance) is decentralized, then the transfer of an unemployed person from one scheme to the other may incur additional administrative costs. A third potential drawback of decentralization is that local politicians may be less competent than politicians at the more central level. Results in Barankay and Lockwood (2007) indicate that decentralization is more effective when the local government is competent. A fourth argument found in the literature is that decentralization may lead to increased pressure from local interest groups. This may distort policy choice and waste public funds. Bardhan and Mookherjee (2000) however show that the link between decentralization and lobbying is ambiguous, i.e., the link can be either negative or positive.

The fifth potential drawback of fiscal decentralization is that it may induce spillovers between different local governments (Lockwood, 2002; Besley and Coate, 2003) or between a local government and the central government. That is, local governments may ignore potential external benefits, or try to divert costs to other governments. Solutions to the case of spillovers between local governments, or horizontal fiscal externalities, are in principle quite straightforward, ${ }^{5}$ although not easy to implement (Boadway and Shah, 2009). A particular problem is that it is often difficult to determine the exact size of the spillover. The case of spillovers between local and central government, or vertical fiscal externalities, has received less attention. The focus is on tax externalities (see, e.g., Keen, 1998) while vertical externalities on the expenditure side have hardly received any attention at all. In this study, we focus precisely on this last aspect of fiscal decentralization. Did the decentralization of social assistance in the Netherlands lead to an increased use of centrally administered social insurance?

Our empirical analysis makes use of data at the municipality level gathered by Statistics Netherlands and the national administration for social insurance (UWV). The data set contains the inflow into SA and DI, the outflow from SA, and variables that may influence these flows during the period 2001-2008. A simultaneous model for the three flows is estimated. The focus is on the fraction of SA flows that are diverted to DI. The identification of this fraction is based on the sensitivity of DI inflow to (lagged) SA volume. SA volume should under normal circumstances not impact DI inflow, given that we control for 'true' disability risks at the municipality level. The observed risk factors include population characteristics, such as education, general disability risk, and demographic and labour market indicators. Moreover, the use of panel data allows us to control for unobserved disability risks. Robustness checks with respect to endogeneity of our instrument, serial correlation, the error distribution, and unobserved heterogeneity are included. In all estimations, we find that the sensitivity of DI inflow to SA volume has significantly increased following the fiscal decentralization of SA. Results imply that at least one third, and possibly more than half, of the entire inflow into the DI scheme in the years 2006-2008 was in fact diverted from SA. These results shed new light on the driving forces behind increasing DI enrolment rates, which are also observed elsewhere and sometimes tentatively linked to vertical externalities between different layers of government. The negative externality found in this paper is sufficiently large that it cannot be neglected when assessing whether the fiscal decentralization of SA was a success.

\footnotetext{
${ }^{5}$ Dafflon (2008) mentions three: (i) compensatory subsidies, (ii) redefining the borders of the local governments, and (iii) restrictions to exit and entry of the public service.
} 
The structure of this paper is as follows. In Section 2, we describe the Dutch institutional context. We then describe our data set and empirical approach in more detail in Sections 3 and 4, respectively, and present the estimation results in Section 5. We summarize and discuss our conclusions in Section 6.

\section{Social Assistance and Disability Insurance in the Netherlands}

\subsection{Social Assistance (SA)}

Social Assistance is the basic welfare scheme in the Netherlands. Roughly speaking, anyone who is on the job market and 'actively' looking for work is entitled to Social Assistance (SA). Claims are means tested; household wealth cannot exceed about 5,000 euros per person, and household income must be below SA level. In general, all other welfare and insurance schemes take precedence. For instance, a recently unemployed worker entitled to Unemployment Benefits will usually not receive Social Assistance. SA benefits can be claimed from the local municipality's Social Service only after registering as unemployed with the administration responsible for employee insurance schemes (UWV). SA recipients are obliged to apply for work and accept any (reasonable) offer. In practice, the latter is not enforced rigorously for recent entrants into the scheme; they are allowed some time to wait for an offer matching their qualifications. The young and poorly qualified are typically offered a job and/or training immediately in so-called 'work first' projects. This group is overrepresented in the SA inflow. They have difficulties establishing themselves on the labour market and, when unemployed, they are usually not entitled to other benefits such as Unemployment Insurance, for they have typically had short work histories and fixed-term contracts. The overall age distribution of the inflow into Social Assistance is shown in Figure 2.1.

Figure 2.1 Age distribution of the inflow into Social Assistance in 2001, 2004 and 2007 (source: Statistics Netherlands).

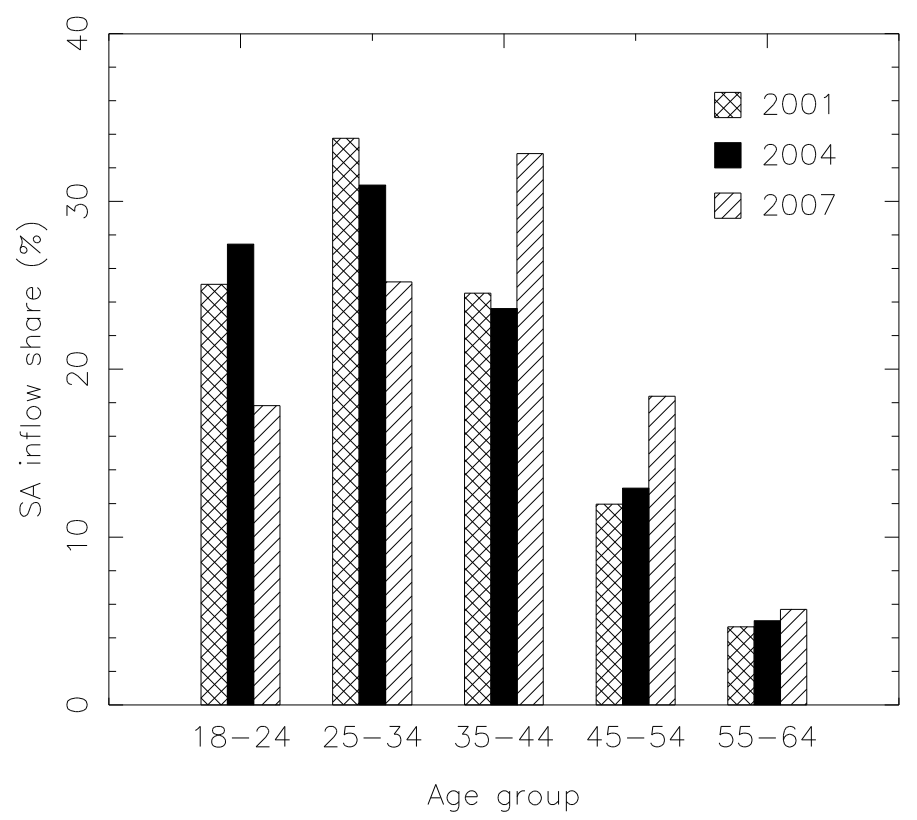

SA benefits amount to $50 \%$ of the minimum wage for single households, $70 \%$ for single parents, and $100 \%$ for couples. In 2008, these amounts equal 630, 882, and 1260 euros per month, respectively (but additional benefits typically apply to cover the cost of housing for the former groups). Until the year 2001, municipalities were almost fully reimbursed by the central government for their actual SA expenses, giving them little incentive to reduce the number of SA recipients. From 2001 onward, the fraction of SA expenditure that is reimbursed has been gradually reduced. Large and medium-sized municipalities receive predetermined SA budgets based on an expenditures model which takes various social and economic characteristics as inputs. Small municipalities 
receive SA budgets based on (but not necessarily equal to) historical expenses. Deficits have to be covered by municipalities' own cash flows (e.g., local taxes) while surpluses can be freely spent. The main transition towards decentralized financial responsibility took place in 2004. As of 2007 the expenditures model fully determines the SA budgets for municipalities larger than 40,000 inhabitants. Municipalities smaller than 25,000 (before 2008: 30,000) receive budgets based on historical expenditure, and an interpolation rule applies to municipalities of intermediate size. Figure 2.2 depicts the introduction of SA budgeting as a function of municipality size. As of 2008 about $85 \%$ of the total budget for Social Assistance in the Netherlands is based on the expenditures model. The remaining $15 \%$ is budgeted based on historical expenses.

Figure 2.2 Timeline of introduction of Social Assistance budgeting, as a function of municipality population. Prior to $2001,90 \%$ of actual SA expenditure was reimbursed by the central government. As of 2004 , municipalities only receive predetermined SA budgets and carry full financial responsibility for deficits (source: Van Es, 2010).

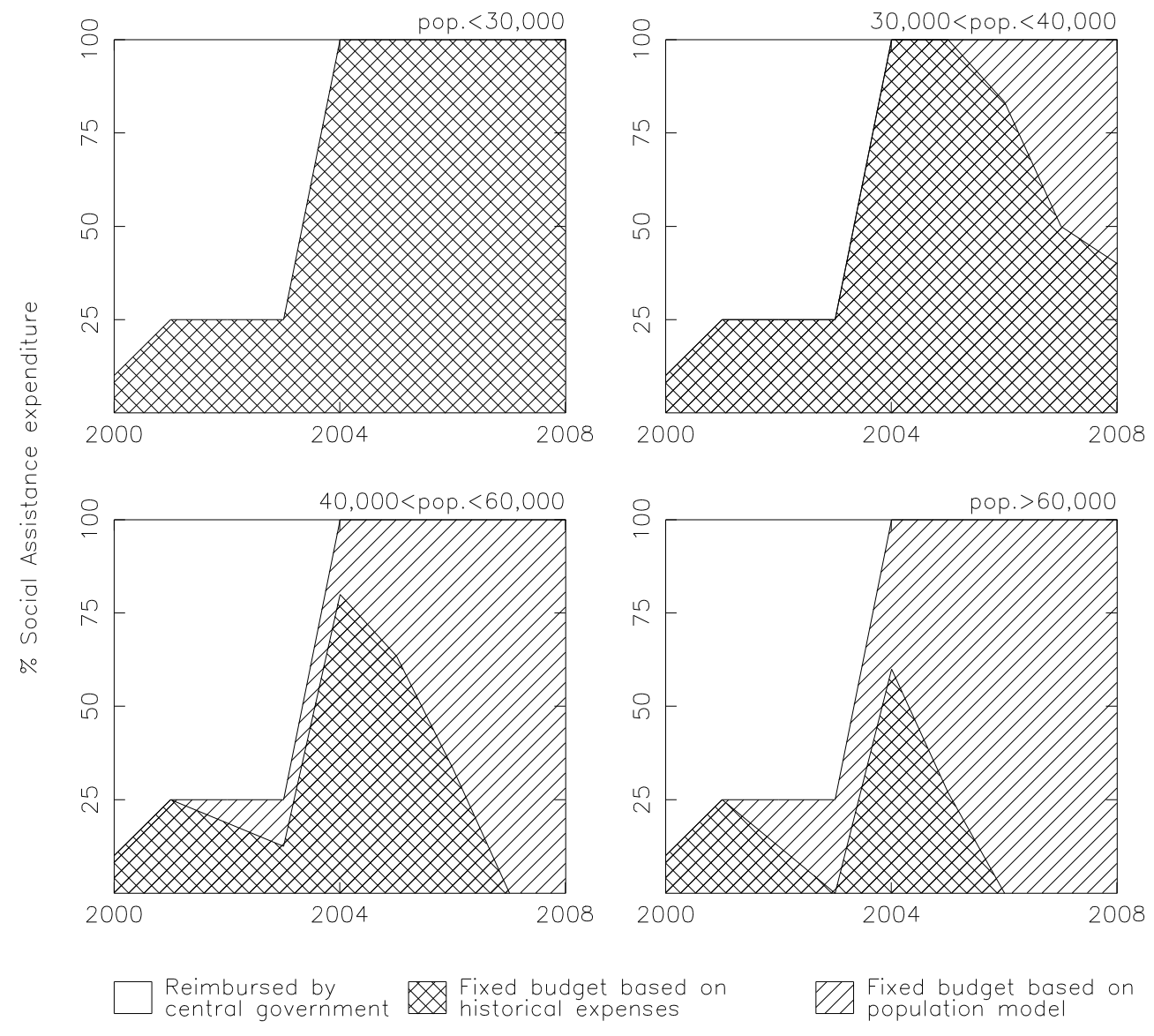

\subsection{Disability Insurance (DI)}

Disability Insurance schemes in the Netherlands are administered by the national social insurance administration UWV. These schemes insure the individual's earnings capacity. The two most important schemes are for employees and for persons with no employment history. The latter is central to this paper, and will simply be referred to as DI. Benefits for employees depend on the actual loss of earnings capacity; benefits for persons with no employment history depend on the minimum wage. The employee scheme is funded by employer and employee premiums, while the DI scheme is funded directly from national tax revenues. Local governments bear no financial responsibility. The DI scheme is open to those who were disabled before the age of 18 and to students who become disabled before the age of 30. Apart from the requirement of being disabled for at least 
$25 \%$, defined as having an earnings capacity of no more than $75 \%$ of the minimum wage, there are fewer conditions than for Social Assistance. Most importantly, households are not means tested, and there is no job search or training requirement if fully disabled. If the DI recipient does find a job (potentially subsidized), his or her income may reach $120 \%$ of the minimum wage before the DI allowance is trimmed, so as to provide an incentive to work if capacity allows. The DI payout is slightly higher: $75 \%$ of the minimum wage when fully disabled, compared to $50 \%$ (or $70 \%$ for singles) for SA, but additional benefits for SA recipients typically offset this difference. By design of the scheme, DI inflow mostly occurs between the ages of 18 and 30. Since the SA inflow is also skewed towards the young (see figure 2.1), there is substantial overlap in terms of age.

\subsection{Recent trends}

Figure 2.3 shows the nationally aggregated inflow into the DI scheme. It features a pronounced upward trend. The inflow has increased since the late 1990s, and the increase started to accelerate in 2001. The biggest jump was in $2006(+30 \%)$. The scheme started in 1976, so the first entrants will reach the age of 65 in 2023, at which point they will transfer to the state pension scheme. However, because the inflow has increased steadily in recent years the scheme will not reach its structural level before 2040 (Van Sonsbeek, 2011).

Figure 2.3 In- and outflow of Social Assistance (SA) and Disability Insurance (DI), per year (source: Statistics Netherlands, UWV).

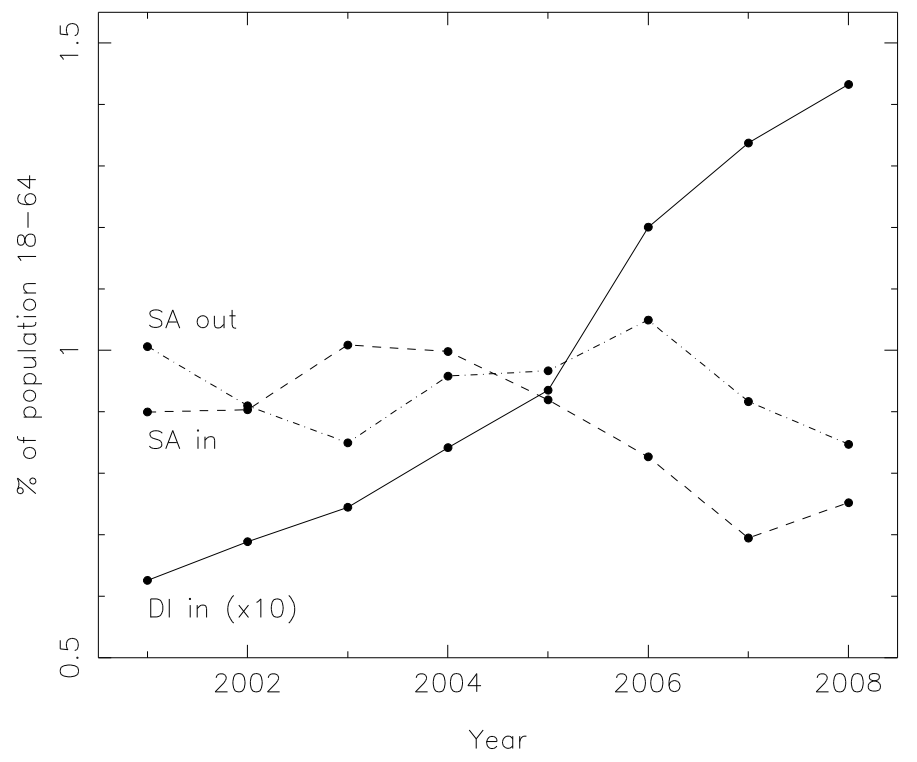

Analysis of a sample of files over the period 2002-2006 for four selected municipalities (UWV, 2007) has shown that, in 2006, the majority of those flowing into DI came directly from school (32\%), mostly at the age of 18 or 19 (67\% of the total). Further large numbers came from 'other institutions' (21\%), Social Assistance $(14 \%)$, and home $(11 \%)$. These fractions vary over the years. There is a remarkable increase in the flow coming from Social Assistance, which increased by $77 \%$ in 2006. This does not include those who applied for Social Assistance, but were diverted directly to DI. The inflow of persons with physical disabilities has remained fairly constant, while the inflow of persons with (mild or very mild) mental impairments has increased. The latter categories include, for example, spectrum disorders such as ADHD (Attention Deficit Hyperactivity Disorder) and ASD (Autism Spectrum Disorder). In the above sample for 2006, $16 \%$ of those flowing into DI had an indication of a physical disability. For the subset coming from Social Assistance, this figure was 8\% (UWV, 2007). 
The increased flow towards DI may be related to the SA funding reforms described in the previous section. Financial responsibility for DI has remained with the central government while financial responsibility for SA has shifted to local governments. This may have given local governments an incentive to try and divert SA recipients to DI and other schemes. In fact, private companies have started to offer services to screen municipalities' databases for SA recipients that can potentially be redirected to DI (UWV, 2007). There may, however, be other factors. For instance, it has been remarked that the number of children going to practice schools or advanced special schools intended for children with learning difficulties has increased over the last decade. Roughly half of all children leaving these schools flow directly into DI, and this percentage may have increased due to improved information services targeting these groups (UWV, 2007).

\section{Data}

Our data set is a balanced panel of administrative data of all Dutch municipalities over the period 2001 to 2008 , covering yearly SA inflow and outflow rates and DI inflow rates, as well as a variety of socio-economic indicators. The data are obtained from Statistics Netherlands (CBS) and from the national administration of employee insurance schemes in the Netherlands (UWV). They cover, in principle, the entire Dutch population. Outflow out of DI is not included as a variable since it is low, fairly constant, and not directly relevant for answering our research question. Several variables related to the regional job market (our business-cycle indicators) were obtained at the so-called 'COROP' cluster level, which is a higher level of aggregation than the municipality level. COROP clusters cover an average of 11 neighbouring municipalities, typically arranged around an urban core, but have no particular hierarchical structure otherwise. During the period of observation several municipalities merged (of the 504 that existed in 2001), so for each year the data have been recompiled according to the municipality boundaries as of January 1st 2009 (441 in total). The smallest municipality, the island of Schiermonnikoog, was excluded because of poor statistics, leaving 440 units in the panel with a total of 3520 data points for the 8 -year period.

Table 3.1 Sample statistics, unweighted $2001 \& 2008$ cross sections $(N=440)$

\begin{tabular}{|c|c|c|c|c|c|c|c|c|}
\hline \multirow[b]{2}{*}{ Variable } & \multicolumn{4}{|c|}{2001} & \multicolumn{4}{|c|}{2008} \\
\hline & Mean & Std. Dev. & Min & Max & Mean & Std. Dev. & Min & Max \\
\hline Inflow SA $\left(S_{\text {in }}\right)^{1}$ & 0.60 & 0.40 & 0.00 & 2.48 & 0.54 & 0.37 & 0.00 & 2.43 \\
\hline Outflow SA $\left(S_{\text {out }}\right)^{1}$ & 0.65 & 0.46 & 0.00 & 2.84 & 0.59 & 0.41 & 0.00 & 2.65 \\
\hline Inflow DI $\left(D_{\text {in }}\right)^{1}$ & 0.06 & 0.04 & 0.00 & 0.38 & 0.13 & 0.06 & 0.00 & 0.50 \\
\hline Immigrant population $^{1}$ & 11.71 & 6.84 & 1.95 & 53.25 & 12.45 & 7.38 & 2.47 & 49.21 \\
\hline Low-skilled workers $^{2,5}$ & 28.48 & 4.00 & 18.27 & 39.44 & 24.04 & 3.43 & 17.39 & 30.84 \\
\hline DI Other ${ }^{1}$ & 7.07 & 1.65 & 3.51 & 13.41 & 5.01 & 1.23 & 2.44 & 9.62 \\
\hline Urbanisation $^{3}$ & 33.39 & 34.38 & 0.00 & 100.00 & 36.10 & 34.44 & 0.00 & 99.74 \\
\hline Rented housing (\%) & 36.87 & 10.17 & 14.16 & 81.44 & 33.73 & 7.95 & 13.15 & 68.04 \\
\hline Single parents (\%) & 12.24 & 3.86 & 6.88 & 38.25 & 14.69 & 4.25 & 7.42 & 37.94 \\
\hline SA volume $(1-\mathrm{lag})^{1}$ & 1.79 & 1.33 & 0.34 & 10.57 & 1.57 & 1.08 & 0.28 & 7.98 \\
\hline Aged $18-19^{1}$ & 3.65 & 0.52 & 2.40 & 7.07 & 3.73 & 0.49 & 1.30 & 6.92 \\
\hline Aged $20-29^{1}$ & 17.98 & 3.05 & 10.91 & 35.89 & 16.06 & 3.30 & 5.56 & 35.40 \\
\hline Outflow UI (\%) $)^{4,5}$ & 65.81 & 5.78 & 54.69 & 79.55 & 83.19 & 4.80 & 71.43 & 100.00 \\
\hline GDP growth (\%, 1-lag) ${ }^{5}$ & 3.99 & 1.57 & 1.10 & 9.00 & 3.64 & 1.66 & -2.60 & 8.80 \\
\hline
\end{tabular}


Observed variables include the relative volumes of the immigrant population, low-skilled working population, disability benefits recipients (other than those in the DI scheme for the young considered here), degree of urbanisation, rented housing, one-parent families, Social Assistance recipients, 18-19 year olds, 20-29 year olds, regional GDP growth rate, and outflow out of unemployment benefits. Sample statistics for the 2001 and 2008 cross sections are shown in Table 3.1. About $0.6 \%$ of the population aged 18-64 flow into and out of SA each year; for DI the yearly inflow rate is $0.1 \%$ on average. These figures differ substantially between municipalities. The inflow into DI in 2008 is twice as high as in 2001, while the SA flows do not change much; this reflects the trends seen in Figure 2.1. The intermediate years (2002-2007) largely follow the trends observed in Table 3.1 for all variables; variation between municipalities is typically much larger than variation over time within municipalities. There are only few zeros in the SA and DI flows: about $1 \%$ of municipalities have zero SA inflow, SA outflow or DI inflow in a given year.

\section{Empirical strategy}

\subsection{Model}

Substitution from SA to DI may occur in two different ways. First, municipalities may redirect SA applicants 'at the gate', so that SA inflow is substituted with DI inflow. Second, municipalities may go through their SA files to see if anyone may be eligible for DI benefits. This way, an increase in DI inflow is directly linked to an increase in SA outflow. Formally, substitution of SA with DI in municipality $i$ at time $t$ can be written as:

$$
\begin{aligned}
& S_{\text {in }, i t}=1-\lambda_{t} s_{i n, i t} \\
& S_{\text {out }, i t}=1+\mu_{t} s_{\text {out }, i t} \\
& D_{\text {in }, i t}=d_{i n, i t}+\lambda_{t} s_{i n, i t}+\mu_{t} s_{\text {out }, i t}
\end{aligned}
$$

All flows are expressed as fractions of the total population aged 18-64. The observed flows into SA, out of SA, and into DI are written as $S_{\text {in }}, S_{\text {out }}$, and $D_{\text {in }}$ respectively, and the corresponding 'natural' flows are written as $s_{\text {in }}$, $s_{\text {out }}$, and $d_{i n}$. Substitution between SA and DI is parameterized by $\lambda$ and $\mu$. The observed flow into SA is the natural flow minus fraction $\lambda$, and the observed flow out of SA is the natural flow plus fraction $\mu$. Both lead to an increased observed inflow into DI.

The natural flows into and out of SA and into DI are assumed to (potentially) depend on a set of control variables $x_{0}$. In addition, a set of identifying variables $x_{b}$ are assumed to affect the natural in- and outflow of SA but not the natural inflow into DI. The natural flows into and out of SA and into DI are modelled as:

$$
\begin{aligned}
& s_{i n, i t}=x_{0, i t} \beta_{0 s}+x_{b, i t} \beta_{b s}+u_{s, i t} \\
& s_{\text {out }, i t}=x_{0, i t} \beta_{0 f}+x_{b, i t} \beta_{b f}+u_{f, i t} \\
& d_{i n, i t}=x_{0, i t} \beta_{0 d}+u_{d, i t}
\end{aligned}
$$

where the error terms $u \sim N\left(0, \Sigma_{0}\right)$ may be correlated. The combination of (4.1) to (4.6) results in the following model for the observed flows:

$$
\begin{aligned}
& S_{i n, i t}=x_{0, i t} \gamma_{0 s}+x_{b, i t} \gamma_{b s}+v_{s, i t} \\
& S_{o u t, i t}=x_{0, i t} \gamma_{0 f}+x_{b, i t} \gamma_{b f}+v_{f, i t} \\
& D_{i n, i t}=x_{0, i t} \gamma_{0 d}+x_{b, i t} \gamma_{b d}+v_{d, i t}
\end{aligned}
$$


with correlated error terms $v \sim N(0, \Sigma){ }^{6}$ The parameters in $\gamma$ and $\Sigma$ can be expressed in terms of the parameters in $\beta, \Sigma_{0}$ and the substitution parameters $\lambda$ and $\mu$ (see Appendix A). These expressions will be used to determine the substitution parameters $\lambda$ and $\mu$ from the estimated coefficients in $\gamma$. A minimum of two identifying variables have to be included in $x_{b}$ in order to have simultaneous identification of the parameters $\lambda$ and $\mu$. Alternatively, we can assume that either $\lambda$ or $\mu$ equals zero, thereby (hypothetically) ascribing all observed substitution of DI for SA to either diverted outflow out of SA or diverted inflow into SA. In this case $x_{b}$ needs to have a minimum of one element.

\subsection{Identification}

The identifying variables in $x_{b}$ must impact the natural SA flows, but not disability risk (the 'natural DI inflow'). They should not influence disability risk provided that we control for (potential) true risk factors via $x_{0}$. We will use the population fraction receiving Social Assistance in the previous period, $\mathrm{SA}_{-1}$, as the identifying variable $x_{b}$. This variable is likely correlated with SA flows, but it should not have any causal effect on disability risk. Correlation between $\mathrm{SA}_{-1}$ and disability risk is unlikely because we control for both observed and unobserved disability risk factors using the panel dimension of our data. Any effect of $\mathrm{SA}_{-1}$ on DI inflow is then interpreted to be due to municipalities diverting potential SA recipients to DI. In other words, a significantly nonzero effect $\gamma_{b d}$ is a direct sign of substitution via $\lambda$ and/or $\mu$.

The control variables may influence both the natural DI inflow and the SA flows. The control variables should (ideally) include all population characteristics that influence the natural DI inflow or 'true' disability risk. As an important control variable, we include the fraction of the population aged 18-64 who receive disability benefits excluding those receiving benefits from the DI scheme for the young considered in this paper. The assumption is that this 'DI Other' rate should correlate strongly with a broad range of population characteristics that influence true disability risk. Age is a second important risk factor that has to be controlled for, since the DI scheme is specifically for individuals with no employment history. Because DI benefits can be claimed from age 18, we include the fraction of 18-19 year olds in the population aged 18-64 (see also Section 2). Since the DI scheme is further intended for students who become disabled before the age of 30 , we also include the population fraction aged 20-29 as a control variable. Individuals aged 30 and over are not expected to flow into the DI scheme under consideration. As further control variables we include the fraction of jobs in the region that are classified as low skilled, the population fraction living in urban areas, the fraction of housing that is rented, the fraction of single-parent families, and the population fraction of immigrants.

In addition to these potential population risk factors, we allow for business-cycle effects and control for them in two ways. First, we have allowed for some 'true' correlation between the SA in- and outflows and the DI inflow via the correlated error terms of the three natural flow equations (4.4)-(4.6). Second, we add a set of regional job-market indicators to the control variables $x_{0}$, namely (lags of) regional GDP growth and outflow out of Unemployment Insurance (UI). Thus we allow (but do not require) the business cycle to be a true disability risk factor, arguing that a young person with relatively mild impairments may be able to find or hold on to a job more easily if the economy in the region is booming.

\subsection{Estimation}

The model consists of a structural form, (4.4)-(4.3), and a reduced form, (4.7)-(4.9). We obtain the parameters of the structural model, which include the substitution parameters $\lambda$ and $\mu$, in two steps. In the first step, the reduced-form parameters $\theta_{R}=\{\gamma, \Sigma\}$ in (4.7)-(4.9) are estimated from the data using Maximum Likelihood,

\footnotetext{
${ }^{6}$ This model is a generalization of the models used in Hassink et al. (1997) and Koning and Van Vuuren (2010).
} 
giving $\hat{\theta}_{R}$. An estimate of the full covariance matrix of $\theta_{R}$ is also obtained (the inverse Hessian of the negative $\log$-likelihood at the maximum). In the second step, the structural parameters $\theta=\left\{\beta, \lambda, \mu, \Sigma_{0}\right\}$ in (4.4)-(4.3) are estimated using a Minimum Distance estimator. Denote expressions of the reduced-form parameters in terms of the structural parameters as $\theta_{R}=g(\theta) .{ }^{7}$ A consistent estimate of $\theta$ then follows from minimizing the distance between the first-step estimator $\hat{\theta}_{R}$ and $g(\theta)$ :

$$
S^{2} \theta=\left[\hat{\theta}_{R}-g \theta\right] \hat{\Omega}_{R}^{-1}\left[\hat{\theta}_{R}-g \theta\right]^{\prime}
$$

where the metric tensor $\hat{\Omega}_{R}^{-1}$ equals the inverse of the covariance matrix of $\hat{\theta}_{R}$ (see Chamberlain, 1984). The covariance matrix of the structural parameters $\theta$ is estimated as

$$
\hat{\Omega}=\left[\hat{\Gamma}^{\prime} \hat{\Omega}_{R}^{-1} \hat{\Gamma}\right]^{-1}, \text { where } \hat{\Gamma}=\left[\frac{\partial g(\theta)}{\partial \theta^{\prime}}\right]_{\theta=\hat{\theta}} .
$$

\section{Results}

\subsection{Cross-Section Estimation}

We begin by estimating the reduced-form model (4.7)-(4.9) for each yearly cross-section in our panel. We retain maximum flexibility by allowing all coefficients (and constants) to vary per year. Since each equation contains a year-specific constant, time trends, and effects of macroeconomic variables (say an aggregate business cycle effect) are accounted for in the econometric specification. Spurious correlations due to trends in variables, which are a relatively important source of within-municipality variability but small compared to between-municipality variability, are avoided with this approach. On the other hand, we need to be careful with bias due to unobserved heterogeneity between municipalities. This will be further investigated in the next subsection.

Results of the reduced-form estimation for 2008 are shown in table 5.1. The results for other years can be found in the Appendix. As expected, the fraction of the population aged 18-64 receiving Social Assistance in the previous period $\left(\mathrm{SA}_{-1}\right)$ correlates strongly with the $\mathrm{SA}$ flows in the current period. The $\mathrm{SA}_{-1}$ volume also correlates strongly with DI inflow, which is rather more surprising. In the previous sections we anticipated two DI risk indicators, namely the fraction of the population receiving disability benefits excluding the DI scheme under study ('DI Other'), and the population fraction aged 18-19. While these two indeed have a significant, positive effect on DI inflow, their effects are still much smaller than the effect of $\mathrm{SA}_{-1}$. The estimated coefficients on $\mathrm{SA}_{-1}$ therefore suggest substitution. The expected large correlations between $\mathrm{SA}_{-1}$ and the SA flows 'spill over' to the DI inflow equation, as in Eq. (4.1)-(4.3), causing the unexpected effect of $\mathrm{SA}_{-1}$ on DI inflow. It can be seen from the relative effects of $\mathrm{SA}_{-1}$ (Table 5.1) that a spillover of order $10 \%$ from either $\mathrm{SA}$ outflow or SA inflow to DI inflow may explain the observed effect of $\mathrm{SA}_{-1}$ on DI inflow in 2008.

In practice, substitution between SA and DI may occur through both SA inflow and SA outflow. With just one identifying variable ( $\mathrm{SA}_{-1}$ ), we cannot estimate both substitution parameters $\lambda$ and $\mu$ simultaneously. Unfortunately, it is difficult to earmark additional identifying variables that (1) significantly influence SA inflow, SA outflow and DI inflow; (2) are in theory not expected to influence the 'natural' DI inflow; and (3) are not expected to correlate strongly with the $\mathrm{SA}_{-1}$ variable. The reason is simple: one expects both diverted flows from SA to DI to be very similar in terms of underlying population characteristics, hence any two identifying variables are expected to be strongly correlated. This makes it unlikely that $\gamma_{b s}$ and $\gamma_{b f}$ in Eqs. (4.7)-(4.8) will be

\footnotetext{
${ }^{7}$ See Appendix A.
} 
(significantly) linearly independent as required for simultaneous identification of $\lambda$ and $\mu$. Fortunately though, this issue does not hamper our main conclusions since we are first and foremost interested in total substitution between the two schemes. In this case one instrument suffices to identify total substitution.

Table $5.1 \quad$ Estimates ( $\mathrm{x} 100), 2008$ cross section $(\mathrm{N}=440)$

\begin{tabular}{|c|c|c|c|c|c|c|}
\hline \multirow[t]{2}{*}{ Regressor } & \multicolumn{2}{|c|}{ SA Inflow $\left(S_{\text {in }}\right)$} & \multicolumn{2}{|c|}{ SA Outflow $\left(S_{\text {out }}\right)$} & \multicolumn{2}{|c|}{ "DI Inflow $\left(D_{\text {in }}\right)$} \\
\hline & Coeff. & Std. Err. & Coeff. & Std. Err. & Coeff. & Std. Err. \\
\hline \multicolumn{7}{|c|}{ Reduced form estimates } \\
\hline Constant & -0.227 & 0.201 & -0.030 & 0.193 & -0.067 & 0.069 \\
\hline Immigrant population & $-0.441^{*}$ & 0.189 & $-0.716^{*}$ & 0.181 & $-0.191^{*}$ & 0.065 \\
\hline Low-skilled workers $^{\dagger}$ & $0.752^{*}$ & 0.359 & $0.900^{*}$ & 0.364 & 0.069 & 0.153 \\
\hline DI Other & 0.565 & 0.697 & -1.047 & 0.670 & $1.562^{*}$ & 0.239 \\
\hline Urbanisation & 0.021 & 0.032 & -0.006 & 0.030 & 0.019 & 0.011 \\
\hline Rented Housing & $-0.393^{*}$ & 0.153 & -0.253 & 0.147 & 0.058 & 0.053 \\
\hline Single Parents & -0.362 & 0.451 & 0.480 & 0.434 & $-0.322^{*}$ & 0.155 \\
\hline Aged 18-19 & -1.240 & 1.800 & $-4.155^{\star}$ & 1.731 & $1.730^{*}$ & 0.620 \\
\hline Aged 20-29 & -0.294 & 0.309 & 0.215 & 0.297 & 0.105 & 0.106 \\
\hline UI Outflow ${ }^{\dagger}$ & -0.184 & 0.322 & -0.092 & 0.327 & -0.036 & 0.137 \\
\hline UI Outflow-1 ${ }^{\dagger}$ & 0.221 & 0.475 & 0.075 & 0.485 & 0.012 & 0.205 \\
\hline UI Outflow-2 ${ }^{\dagger}$ & 0.509 & 0.502 & 0.264 & 0.510 & 0.075 & 0.214 \\
\hline $\mathrm{GDP}_{-1}^{\dagger}$ & -0.003 & 0.007 & -0.009 & 0.007 & -0.004 & 0.003 \\
\hline $\mathrm{GDP}_{-2}^{\dagger}$ & -0.008 & 0.006 & -0.010 & 0.006 & 0.002 & 0.003 \\
\hline $\mathrm{SA}_{-1} / 100$ & $0.358^{*}$ & 0.013 & $0.381^{*}$ & 0.013 & $0.032^{*}$ & 0.005 \\
\hline \multicolumn{7}{|l|}{ Covariance matrix } \\
\hline$S_{\text {in }}$ & 0.0194 & 0.0013 & 0.0103 & 0.0010 & 0.0005 & 0.0003 \\
\hline$S_{\text {out }}$ & & & 0.0180 & 0.0012 & 0.0003 & 0.0003 \\
\hline$D_{\text {in }}$ & & & & & 0.0023 & 0.0002 \\
\hline \multicolumn{7}{|l|}{ Structural estimates } \\
\hline $\mathrm{SA}_{-1} / 100$ & $0.390^{*}$ & 0.014 & $0.349^{*}$ & 0.013 & - & - \\
\hline$\lambda$ & $0.083^{*}$ & 0.011 & - & - & & \\
\hline$\mu$ & - & - & $0.093^{*}$ & 0.014 & & \\
\hline
\end{tabular}

${ }^{\dagger}$ Regressor at the COROP aggregate level; standard errors corrected for bias due to spatial correlation within clusters according to Moulton (1990).

The bottom part of table 5.1 shows the structural-form estimates of the model (4.1)-(4.6) obtained by minimum distance estimation of (4.10), under the identifying assumption that the observed effect of SA $\mathrm{A}_{-1}$ on DI inflow is either due to substitution from SA inflow to DI inflow (via $\lambda$ ), or due to substitution from SA outflow to DI inflow (via $\mu$ ). We see that a substitution fraction of about $9 \%$ obtains in either case. Since the observed effect of $\mathrm{SA}_{-1}$ on DI inflow may be due to substitution from both SA inflow and SA outflow simultaneously, total substitution may be any convex combination of the two separate estimates. It should be noted that these estimates may be on the high side as we did not take account of unobserved heterogeneity. In the next subsection we will control for that, and see whether total substitution is indeed lower than $9 \%$.

Repeating this analysis for the other years in our data set, we obtain the results shown in Table 5.2 and Figures 5.1-5.4. Figure 5.1 shows the reduced-form estimates of the effect of $\mathrm{SA}_{-1}$ on the three flows. Even more interesting than the large effect of $\mathrm{SA}_{-1}$ on DI inflow per se is the substantial increase we observe in this effect after 2004. The corresponding structural-form estimates of the substitution parameters $\lambda$ and $\mu$ (still assuming that substitution occurs via either diverted SA inflow or increased SA outflow, that is, via either $\lambda$ or $\mu$ ) are shown in Figure 5.2. We see that a threefold increase in substitution, from about 3\% in 2001-2004 to about $10 \%$ in 2006-2008, is needed to explain the observed effects of SA $\mathrm{S}_{-1}$ on DI inflow. Expressed as a percentage of total DI inflow we see that about more than one third of DI inflow appears to be diverted from SA, increasing to two- 
thirds in 2006-2007 (Figure 5.3). Since DI inflow has increased strongly over these years, the absolute number of persons that appear to be diverted from SA has in fact more than doubled, as shown in Figure 5.4. As the solid and dashed line in Figs. 5.3 and 5.4 practically coincide, the separate restricted estimates of $\lambda$ and $\mu$ are directly indicative of total substitution between SA and DI for all years (but we cannot say whether substitution predominantly occurs via diverted SA inflow or SA outflow).

Table 5.2 Substitution parameters and standard errors for the cross-section model

\begin{tabular}{|c|c|c|c|c|c|c|c|c|c|c|c|c|c|c|c|c|}
\hline & & 2001 & & 2002 & & 2003 & & 2004 & & 2005 & & 2006 & & 2007 & & 2008 \\
\hline$\lambda$ & 0.032 & $(0.010)$ & 0.025 & $(0.009)$ & 0.036 & $(0.009)$ & 0.029 & $(0.009)$ & 0.052 & $(0.008)$ & 0.090 & $(0.010)$ & 0.116 & $(0.011)$ & 0.083 & $(0.011)$ \\
\hline$\mu$ & 0.027 & $(0.009)$ & 0.025 & $(0.010)$ & 0.043 & $(0.011)$ & 0.033 & $(0.010)$ & 0.056 & $(0.010)$ & 0.087 & $(0.011)$ & 0.107 & $(0.013)$ & 0.093 & $(0.015)$ \\
\hline
\end{tabular}

Figure 5.1 Estimated effects of a 1\%-point increase in the SA $\mathrm{SA}_{-1}$ rate on the SA inflow, SA outflow, and DI inflow rates, all measured as a percentage of the population aged 18-64 per year.
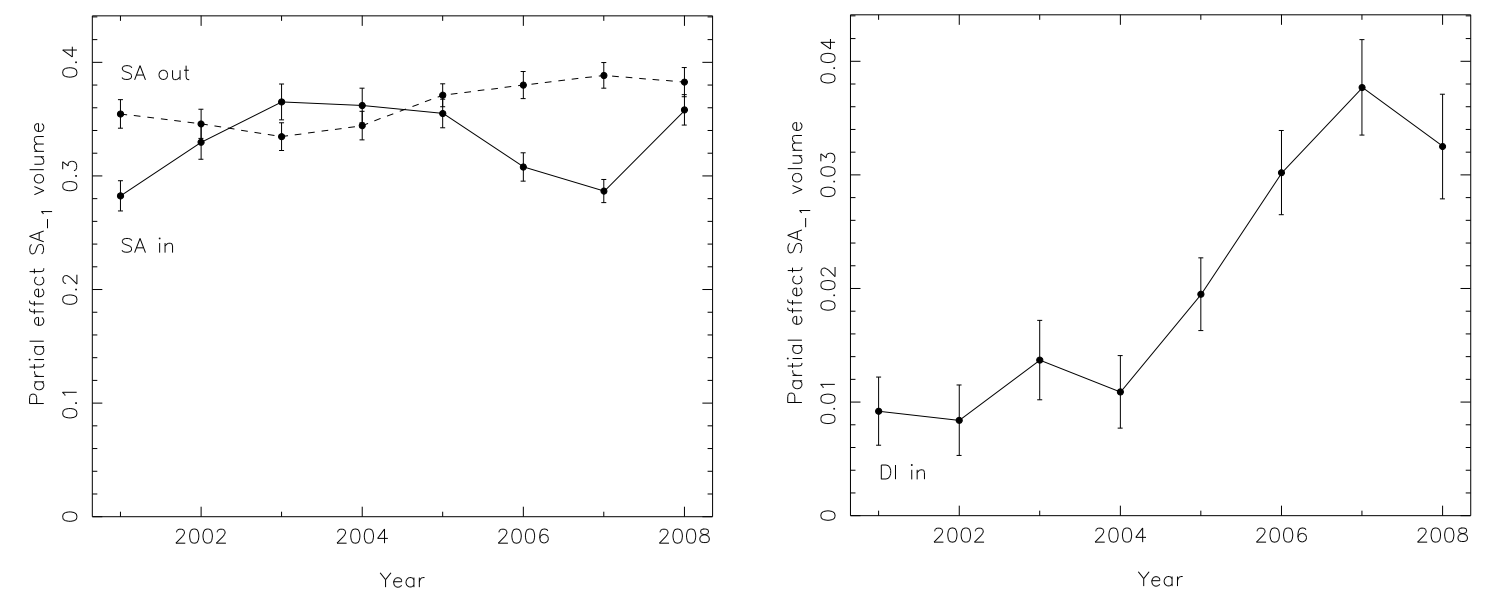

Figure 5.2 Substitution parameters $\lambda$ (fraction natural SA inflow to DI inflow, solid line) and $\mu$ (fraction natural SA outflow to DI inflow, dashed line), assuming in each case that the other parameter is zero.

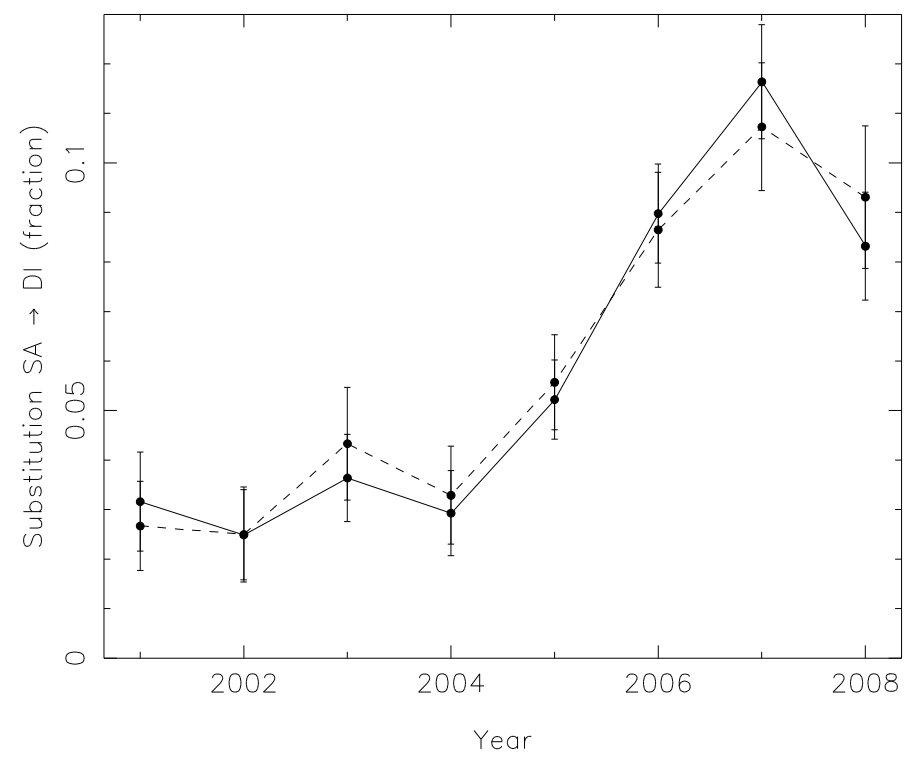


Figure 5.3 Inferred substitution rates as a percentage of total DI inflow, assuming diversion occurs either from SA inflow to DI inflow (solid line), or from SA outflow to DI inflow (dashed line).

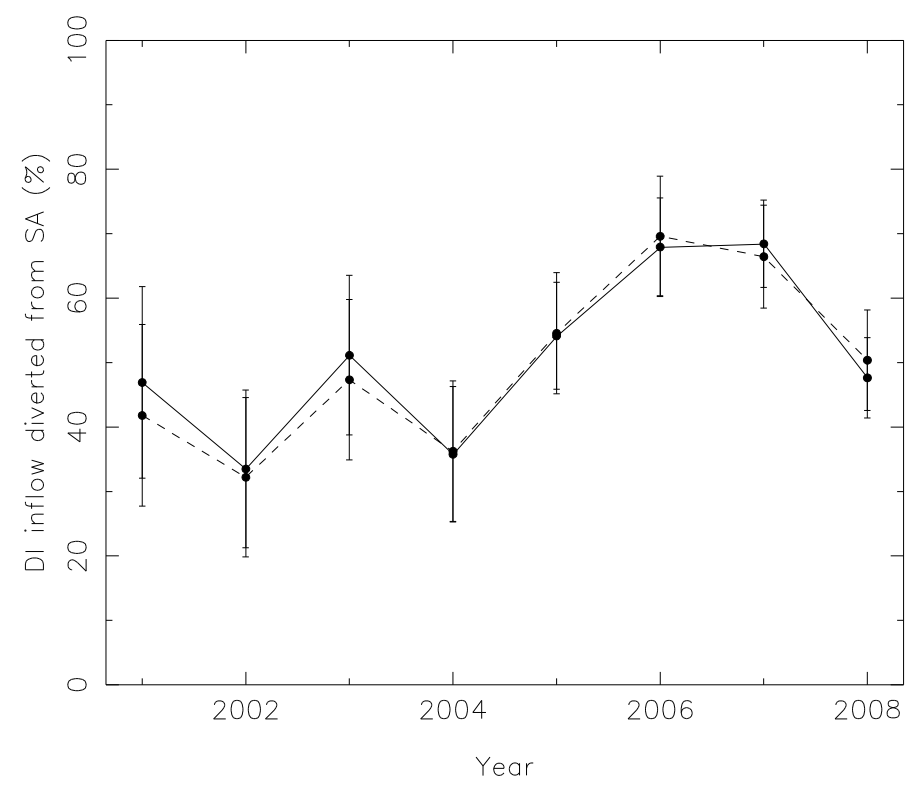

Figure 5.4 Inferred substitution of DI for SA, absolute numbers (meaning of lines as in Figure 5.3).

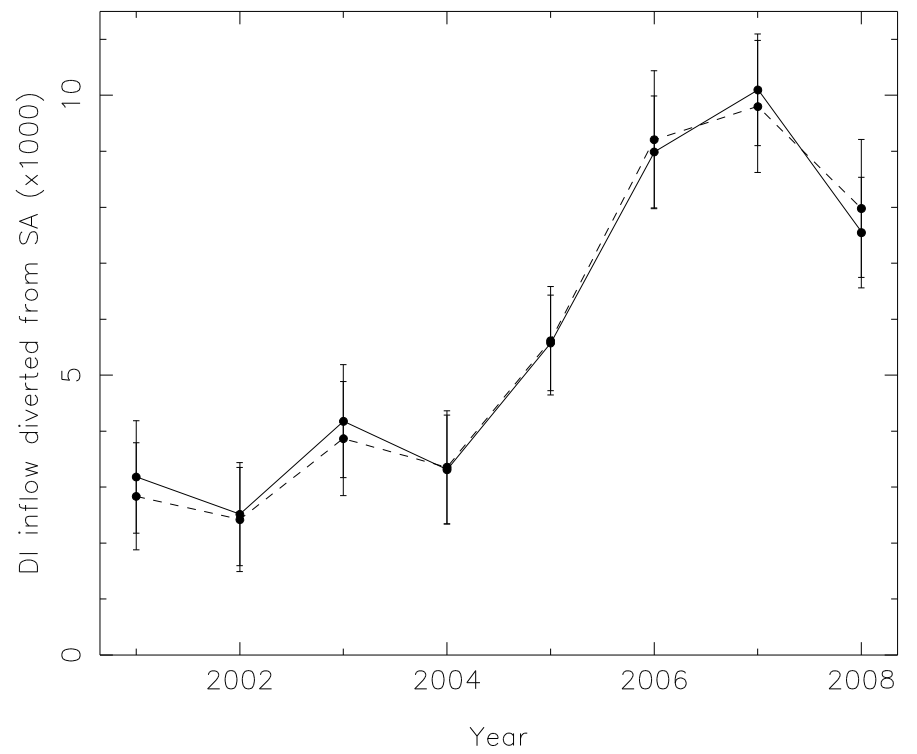

\subsection{Panel Estimation}

In this subsection we address potential shortcomings of the previous cross-sectional estimates, in particular the effects of unobserved heterogeneity. Unobserved heterogeneity correlated with our instrument SA may induce omitted variables bias in the estimates of the substitution parameters. We model time-constant municipality heterogeneity using both random and fixed effects. Our random effects model, which allows for more general serial correlation, largely generates the same results as the cross-section model. Using a fixed effects assumption we are able to derive robust lower bounds for substitution between SA and DI.

\subsubsection{Random effects}

We first allow for unobserved time-constant municipality heterogeneity by estimating a random effects model of all years combined. A municipality-specific error component $u_{i}$ is added to each of the three flow equations. In 
addition, we allow for exponential serial correlation of the time-varying error components. Several mechanisms may cause such serial correlation. Firstly, exogenous shocks to any of the three flows may typically last longer than one period. Secondly, a positive shock to a flow decreases the stock from which this flow originates, which will tend to suppress the flow in subsequent periods. And thirdly, since the SA flows affect the SA stock and, thereby, the model predictions for the flows in subsequent periods via the $\mathrm{SA}_{-1}$ regressor, the model endogenously introduces serial correlation of the errors.

We cannot predict what net serial correlation of the errors will result. In order to keep the number of parameters manageable we assume exponentially weighted error terms, in addition to the random effects terms, as follows:

$$
\begin{aligned}
& S_{i n, i t}=x_{0, i t} \gamma_{0 s, t}+x_{b, i t} \gamma_{b s, t}+u_{s, i}+\sum_{\tau} \rho_{s}^{|t-\tau|} v_{s, i, \tau} \\
& S_{o u t, i t}=x_{0, i t} \gamma_{0 f, t}+x_{b, i t} \gamma_{b f, t}+u_{f, i}+\sum_{\tau} \rho_{f}^{|t-\tau|} v_{f, i, \tau} \\
& D_{i n, i t}=x_{0, i t} \gamma_{0 d, t}+x_{b, i t} \gamma_{b d, t}+u_{d, i}+\sum_{\tau} \rho_{d}^{|t-\tau|} v_{d, i, \tau}
\end{aligned}
$$

where $u_{i} \sim N\left(0, \sigma_{u}\right)$ are the random effects, and $\rho^{|\tau-t|}$ are the weights on the idiosyncratic shocks $v_{i, \tau}$. All coefficients on the explanatory variables, including the constants, remain year-specific to preserve maximum flexibility of the model. Hence, this model is a true generalization of the cross-sections we have estimated in Section 5.1.

Figure 5.5 Inferred substitution of DI for SA with random effects and serial correlation added to the flow equations, absolute numbers (compare Figure 5.4).

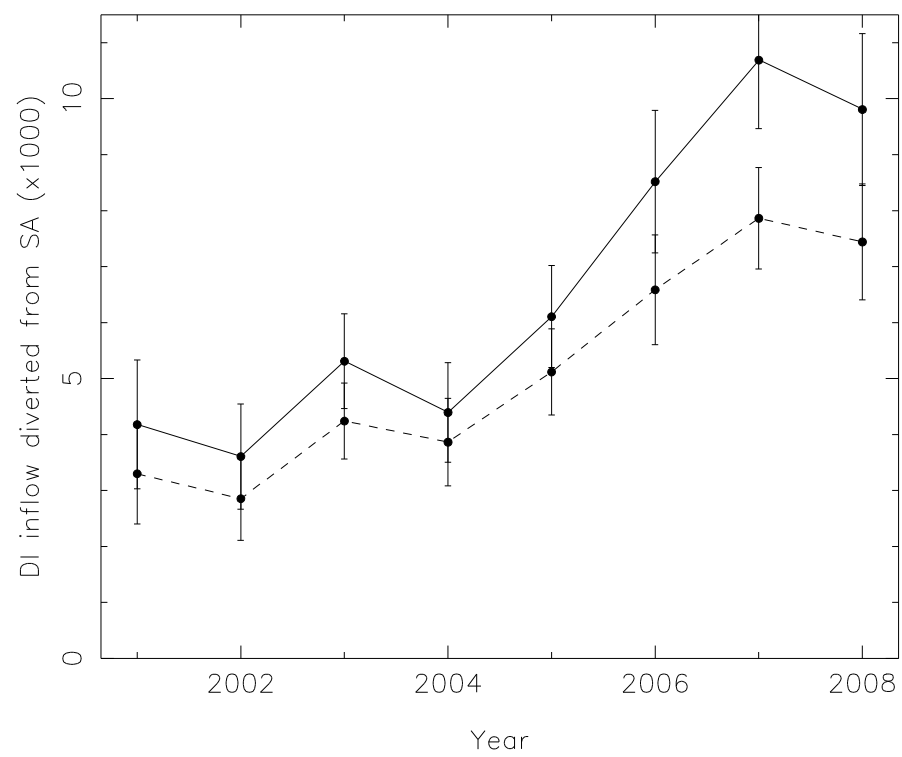

Figure 5.5 shows the substitution estimates we obtain. Estimates of substitution via either SA inflow or SA outflow differ more than in the cross-section analysis: however, recall that total substitution will be a convex combination of the two (Section 5.1), so the results are fully consistent with our cross-section estimates. Serial correlation is statistically significant but fairly small at about 4-5\% for the SA inflow and for the DI inflow, and $13 \%$ for the SA outflow (see Appendix C). The random effects are also significant which suggests the presence of unobserved municipality heterogeneity. However, we find that the idiosyncratic error components dominate for all equations in all years: the variance of the time-varying error component $v_{i t}$ is about twice as large as that of the random effect $u_{i}$ for all equations. This implies that the efficiency loss from estimating yearly cross- 
sections is small. It does not necessarily mean that bias due to unobserved heterogeneity must also be small, so we next estimate bias-robust lower limits for our coefficients of interest using a 'fixed effects' assumption.

\subsubsection{Fixed effects}

To exclude the possibility of bias due to unobserved heterogeneity, we next estimate a 'fixed effects' model. If there should remain unobserved variables that strongly and significantly influence the true risk of being disabled and that happen to correlate strongly with the $\mathrm{SA}_{-1}$ rate rather than with the 'DI Other' rate or any of the other control variables, then the observed effect of $\mathrm{SA}_{-1}$ on DI may be due in part to omitted variables bias.

We employ a fixed effects specification slightly different from the standard model. Rather than assuming that the unobserved components of municipality heterogeneity are constant in time, we assume here that the bias they cause (if any) in the observed variable of interest is constant. The motivation for this fixed effects model is that $\mathrm{SA}_{-1}$ does not change much over the period of observation for a given municipality. Hence the potential bias caused by unobserved population characteristics that also do not change much over this time span can reasonably be expected to be constant. This way, an estimated change in the effect of $\mathrm{SA}_{-1}$ on DI inflow implies that at least the entire change is due to substitution, which puts a lower bound on substitution between SA and DI. The top left panel in Figure 5.6 illustrates this; a technical description is given in Appendix B.

Figure 5.6 Inferred substitution of DI for SA: lower limits based on fixed effects assumption. Top left: illustration of our fixed effects assumption. Top right to bottom right: bias-robust lower limits for substitution parameters, fractions, and numbers for the years 2005-2008 (lower sets of lines, meaning as in Figure 5.3) plotted together with the baseline results of Section 5.1 .
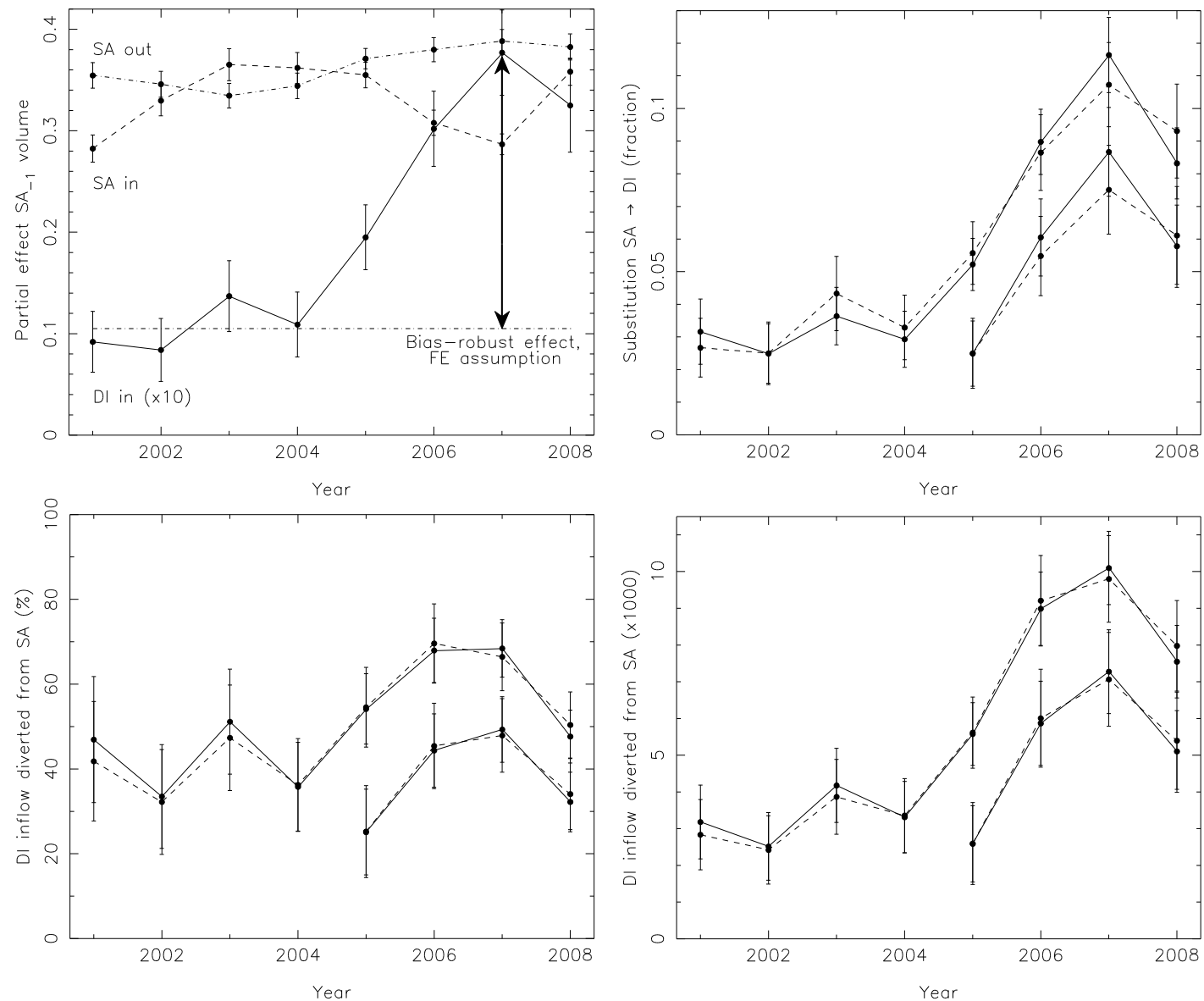

In words: suppose that the observed positive effect of SA - $_{-1}$ on DI inflow in the years 2001-2004 entirely consists of bias due to some omitted variable, which may be a true disability risk factor and, hence, not a valid identifier 
of substitution. Under our fixed effects assumption, this bias is constant. The observed increase in the effect of $\mathrm{SA}_{-1}$ on DI inflow from 2005 onwards must then be due to (increased) substitution, and hence we can estimate lower limits on substitution in the years 2005-2008 that are robust to such bias. Figure 5.6 shows these lower bounds for the two scenarios in which substitution between SA and DI occurs through either SA inflow or SA outflow. We see that, using the change in the effect of $\mathrm{SA}_{-1}$ as a bias-robust identifier of substitution, a minimum of one third of total DI inflow in 2006-2008 were in fact SA (candidate) recipients diverted to DI. This is a conservative estimate; any smaller bias (including a negative one) in the effect of $\mathrm{SA}_{-1}$ on DI inflow implies that actual substitution in 2005-2008 was higher than this. If there is no substantial bias, then our substitution estimates of Section 5.1 hold. We can thus conclude that between one third and two thirds of DI inflow was diverted from SA.

\subsubsection{Robustness checks}

Finally, we check assumptions of our model and their influence on the results. First, we investigate whether the assumed error distribution impacts our estimation results. Second, we test if there is a problem with the endogeneity of $\mathrm{SA}_{-1}$. Finally, we investigate if time-varying omitted variables contaminate our estimation results by instrumenting them with observed control variables.

Table 5.3 Substitution parameters and standard errors for the baseline model and alternative specifications: residual-kurtosis-matched $t(5)$ error distribution, and the $\mathrm{SA}_{-1}$ regressor fixed to $\mathrm{SA}_{2003}$ from 2004 onwards.

\begin{tabular}{|c|c|c|c|c|c|c|c|c|c|c|c|c|c|c|c|c|}
\hline & & 2001 & & 2002 & & 2003 & & 2004 & & 2005 & & 2006 & & 2007 & & 2008 \\
\hline \multicolumn{17}{|c|}{ Cross-section model } \\
\hline$\lambda$ & 0.032 & $(0.010)$ & 0.025 & $(0.009)$ & 0.036 & $(0.009)$ & 0.029 & $(0.009)$ & 0.052 & $(0.008)$ & 0.090 & $(0.010)$ & 0.116 & $(0.011)$ & 0.083 & $(0.011)$ \\
\hline$\mu$ & 0.027 & $(0.009)$ & 0.025 & $(0.010)$ & 0.043 & $(0.011)$ & 0.033 & $(0.010)$ & 0.056 & $(0.010)$ & 0.087 & $(0.011)$ & 0.107 & $(0.013)$ & 0.093 & $(0.015)$ \\
\hline \multicolumn{17}{|c|}{ Random effects model } \\
\hline$\lambda$ & 0.041 & $(0.011)$ & 0.035 & $(0.009)$ & 0.046 & $(0.007)$ & 0.039 & $(0.008)$ & 0.057 & $(0.009)$ & 0.086 & $(0.013)$ & 0.122 & $(0.014)$ & 0.106 & $(0.015)$ \\
\hline$\mu$ & 0.031 & $(0.085)$ & 0.030 & $(0.008)$ & 0.048 & $(0.008)$ & 0.038 & $(0.008)$ & 0.051 & $(0.008)$ & 0.061 & $(0.009)$ & 0.084 & $(0.010)$ & 0.086 & $(0.012)$ \\
\hline \multicolumn{17}{|c|}{ Fixed effects model (lower limits) } \\
\hline$\lambda$ & & & & & & & & & 0.025 & $(0.008)$ & 0.061 & $(0.010)$ & 0.087 & $(0.012)$ & 0.058 & $(0.011)$ \\
\hline$\mu$ & & & & & & & & & 0.025 & $(0.009)$ & 0.055 & $(0.011)$ & 0.075 & $(0.012)$ & 0.061 & $(0.014)$ \\
\hline \multicolumn{17}{|c|}{ t(5)-distributed error terms } \\
\hline$\lambda$ & 0.040 & $(0.008)$ & 0.033 & $(0.008)$ & 0.044 & $(0.007)$ & 0.034 & $(0.008)$ & 0.059 & $(0.008)$ & 0.091 & $(0.010)$ & 0.120 & $(0.011)$ & 0.100 & $(0.012)$ \\
\hline$\mu$ & 0.035 & $(0.008)$ & 0.033 & $(0.008)$ & 0.056 & $(0.010)$ & 0.040 & $(0.010)$ & 0.066 & $(0.010)$ & 0.085 & $(0.010)$ & 0.108 & $(0.012)$ & 0.107 & $(0.015)$ \\
\hline \multicolumn{17}{|c|}{$S A_{-1}$ fixed to $S A_{2003}$ after 2004} \\
\hline$\lambda$ & 0.032 & $(0.010)$ & 0.025 & $(0.009)$ & 0.036 & $(0.009)$ & 0.029 & $(0.008)$ & 0.053 & $(0.008)$ & 0.091 & $(0.011)$ & 0.114 & $(0.012)$ & 0.092 & $(0.012)$ \\
\hline$\mu$ & 0.027 & $(0.009)$ & 0.025 & $(0.010)$ & 0.043 & $(0.011)$ & 0.033 & $(0.010)$ & 0.058 & $(0.010)$ & 0.088 & $(0.012)$ & 0.107 & $(0.014)$ & 0.109 & $(0.017)$ \\
\hline
\end{tabular}

Since we estimate our model using maximum likelihood, we first investigate whether our results are affected by the assumption of normally distributed errors. Inspection of the residuals of our model shows that, while there are no obvious outliers, there is excess kurtosis in all three flow equations (4.7)-(4.9) for all years. We therefore re estimate our model with a multivariate, residual kurtosis matched $t(5)$ distribution for the error terms. The results are shown in Table 5.3 and the left panel of Figure 5.7. The estimates of the substitution parameters increase slightly, but remain close to the original estimates for every year. We conclude that our results are not 
substantially influenced by the assumption of normally distributed errors. If anything, the normality assumption leads to a slightly conservative estimate of substitution.

Secondly, we investigate the potential effect of substitution-induced endogeneity of the $\mathrm{SA}_{-1}$ regressor. The $\mathrm{SA}_{-1}$ regressor, serving as our identifying variable on the right-hand side of the DI inflow equation, will change as persons are diverted from SA to DI. Whether this is a problem for our estimation is a matter of timescales. At the very peak of substitution in 2007, almost 10,000 individuals were diverted to DI from a dynamic SA stock of more than 300,000, implying a timescale of endogenous change of more than 30 years. Changes in substitution rates due to other factors such as changes in incentives or changes in the stock of substitutable persons (a subset of the total SA stock) are expected to happen on much shorter timescales. And in fact, they are observed to happen on much shorter timescales (recall Figure 5.4). We thus expect the endogenous effect to be negligible. We verify this by estimating a simple alternative model in which we fix the $\mathrm{SA}_{-1}$ regressor to $\mathrm{SA}_{2003}$ for all years after 2004. Depletion of the SA stock due to strongly increased diversion to DI after 2004 can then no longer lead to an endogenous increase in the effect of SA-1 on DI inflow. The results are collected in Table 5.3 and the right-hand panel of Figure 5.7. We essentially observe the same increase in substitution as before. We conclude that endogeneity of the $\mathrm{SA}_{-1}$ regressor is not important for the results presented in this paper.

Figure 5.7 Estimated substitution rates for variations on the baseline model, in absolute numbers per year. Left: kurtosis-matched $t(5)$ distribution instead of normal distribution for the error terms. Right: $\mathrm{SA}_{-1}$ regressor fixed to $\mathrm{SA}_{2003}$ from 2004 onwards. Compare with Figure 5.4.
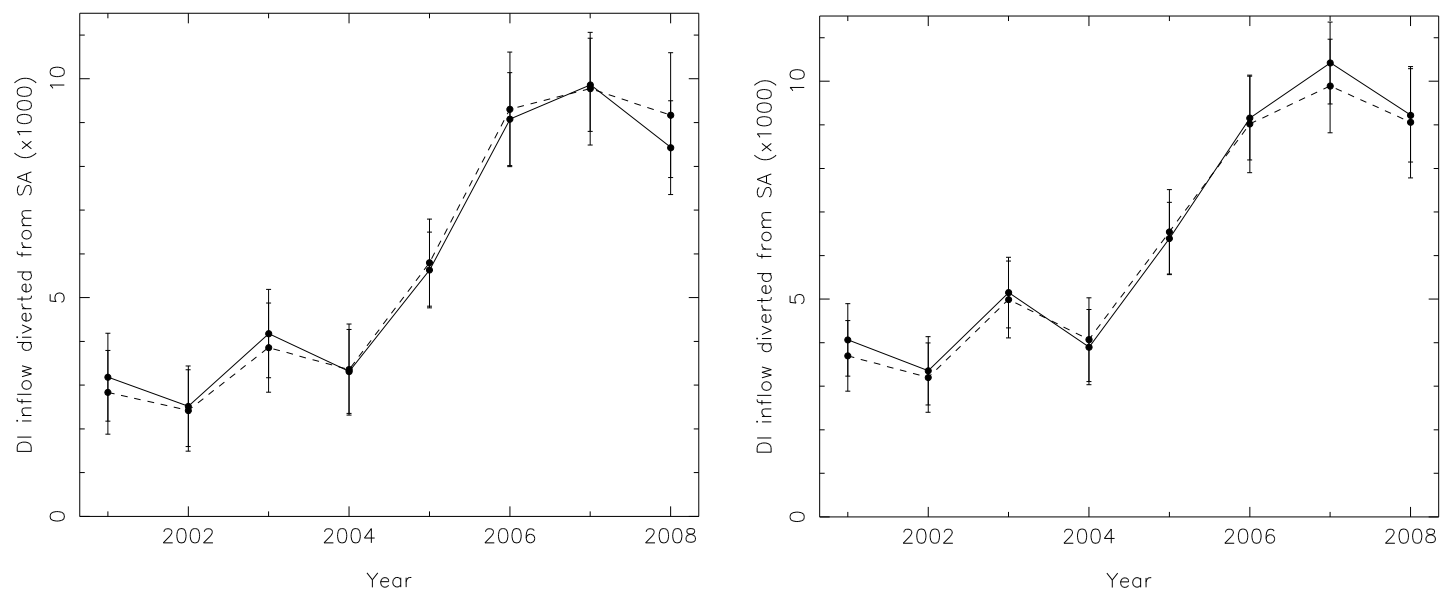

Thirdly, we investigate whether the omission of time-varying explanatory variables has caused bias in the estimation results. Anticipated correlations between observed control variables and potential unobserved timevarying effects allow us to check if the latter could cause omitted variables bias in the estimated substitution parameters. Concretely, it has been hypothesized that an increase in the number of children going to advanced special schools, combined with expanded information services targeting these groups, has contributed to the increase in DI inflow (UWV, 2007). The idea is that many attending these schools apply for DI benefits upon finishing school; the schools may effectively promote the move to DI (see also Section 2). We have no direct data on the number of children going to such schools and the quality of information services provided. But we can anticipate that if such an unobserved time-varying effect has indeed affected the DI inflow over the years, then we will observe an increase in the effect of the 18-19 year old population on DI inflow (recall from Section 2 that DI benefits can be, and often are, claimed from age 18). Figure 5.8 shows this effect over time for our baseline model of Section 5.1. We also include an alternative specification in which the $\mathrm{SA}_{-1}$ regressor was 
omitted in order to give the 18-19 year old population variable every chance to explain the observed DI inflow increase. Clearly, however, no significant upward trend occurs in the effect of the 18-19 year old population. The 18-19 year old population itself has also remained stable between 2001-2008 (see Table 3.1), so it would appear that increased attendance of advanced special schools has had little or no net effect on DI inflow.

Basically, those flowing from these schools into DI would also have entered the scheme if they had not gone to such schools. On the same grounds, we consider it unlikely that unobserved time-varying population characteristics carrying intrinsic disability risk (say genetic or environmental) have affected our results: if they had, we would expect them to have caused an increase in the effect of the 18-19 year old population on DI inflow, which we do not observe. These results strengthen confidence in our estimates of substitution between SA and DI, and in particular the increase after 2004.

Figure 5.8 Effect of population aged 18-19 on DI inflow rate, both as a fraction of population 18-64, in our baseline model. Compare with the effect of $\mathrm{SA}_{-1}$ volume on DI inflow as shown in Figure 5.1. The dashed line shows an alternative specification in which the $\mathrm{SA}_{-1}$ regressor was omitted.

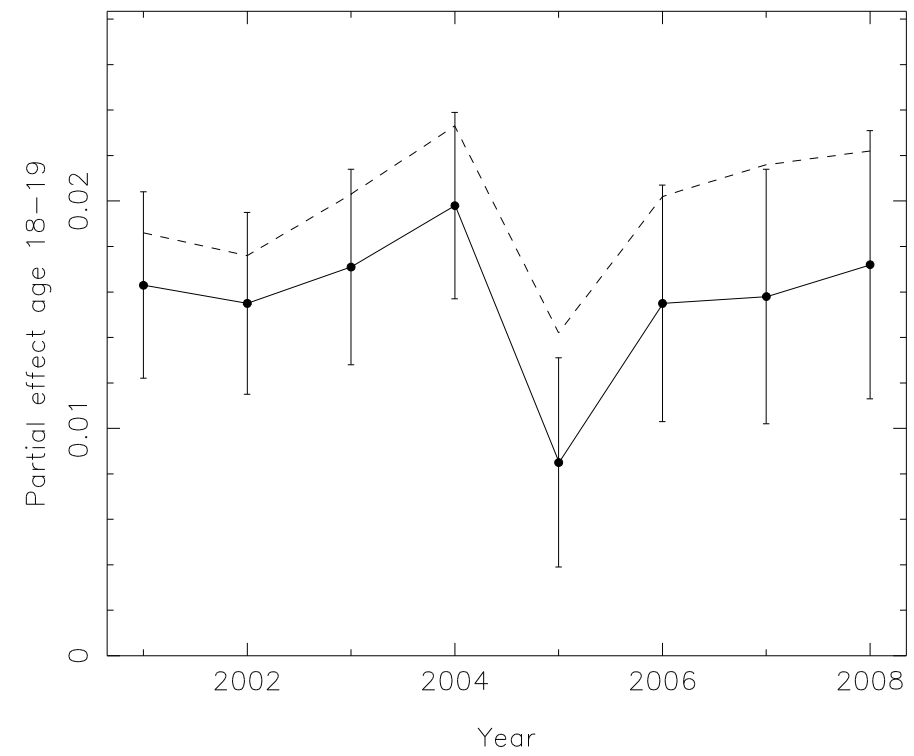

\section{Conclusion}

We have presented a model for, and estimates of, substitution between Social Assistance (SA) and a Disability Insurance scheme for individuals with no employment history (DI) over the period 2001-2008 in the Netherlands, using a balanced panel data set of 440 Dutch municipalities. We find that at least one third of those flowing into the disability insurance scheme in the period 2006-2008 have been diverted from social assistance. Because the inflow into the DI scheme has increased rapidly over the period considered, the absolute number of diversions has more than doubled, mostly over the period 2004-2007. Relaxation of our fixed effects assumption even results in higher estimates of substitution towards DI.

This rapid increase in substitution between the two schemes is strikingly coincident with the social assistance funding reforms that took place over this period, which strongly increased municipalities' financial incentives to reduce their number of social assistance recipients. Since municipalities are not financially responsible for the DI scheme, a causal connection between the two events seems logical. Hence, the increased substitution of disability insurance for social assistance looks to be due to misaligned interests of different levels of government. It is true that substitution may be attractive for the individual as well (see Section 2), but this was also true prior to the decentralization of social assistance in 2004, so individual incentives are unlikely to be the main driver of the observed increase in substitution after 2004. 
The idea behind transferring financial responsibility for social assistance to local government was, naturally, to create incentives for local government to look more carefully at the allocation of social assistance. While this appears to have worked, based simply on the observed lower social assistance volume and inflow (Van Es, 2010), part of the reduction has apparently flowed towards the centrally administered DI scheme (and potentially also to other schemes). The exact mechanism by which local governments have diverted people from social assistance to disability insurance cannot be deduced from our results, but is of secondary importance for this paper. It is likely that the observed substitution consists of two parts: a transitory 'cleaning up' of municipalities' existing SA files, and an increased structural rate of substitution of DI for SA. The substitution estimates for our final year 2008 are slightly (though not significantly) lower than for 2007, suggesting that some transitory effect may have taken place in the early years after the reform. The net result of local governments' actions may well have been a less efficient allocation of welfare expenditure: young people may have been 'written off' for the labour market too quickly. This negative 'vertical externality' shows the need to have a good understanding of the degree to which different welfare schemes can act as substitutes, not just for reforms that alter individuals' incentives but also for reforms that alter the incentives of different layers of government.

A connotation is that we must be careful identifying the increased substitution with increased misuse of the DI scheme since, technically, all DI entrants have been examined medically and are by construction entitled to DI benefits. One could even argue that there was substantial 'hidden disability' in the SA scheme before 2004, which was then discovered and transferred to DI. Nevertheless the idea of 'hidden disability' seems odd, since already $10 \%$ of the total population aged 18-64 were receiving some form of disability benefits in 2004 while only 3.5\% were receiving social assistance. Moreover, individuals have always had incentives to be in the DI scheme rather than the SA scheme, contrary to the typical case of hidden unemployment in disability schemes. After all, the phenomenon of 'hidden unemployment' in disability schemes is well-documented in the literature. ${ }^{8}$

A further reform that has been proposed for the Netherlands is to transfer financial responsibility for DI to local governments as well. This would remove local governments' incentives to divert young people from social assistance to disability insurance. Our study shows that this will likely have an effect, and that further investigation of vertical externalities in social insurance is important for answering the final question: what is the optimal distribution of responsibilities over different layers of government?

\section{References}

Adam, A., M. Delis, and P. Kammas, 2008, Fiscal Decentralization and Public Sector Efficiency: Evidence from OECD Countries, CESIFO Working Paper No. 2364.

Ahmad, E., G. Brosio, and V. Tanzi, 2008, Local Service Provision in Selected OECD Countries: Do Decentralized Operations Work Better? IMF Working Paper WP/08/67.

Autor, D. and M. Duggan, 2003, The rise in the disability rolls and the decline in unemployment, Quarterly Journal of Economics, vol. 118, pp. 157-205.

\footnotetext{
${ }^{8}$ See, e.g., Westerhout (2001), Black et al. (2002), Autor and Duggan (2003), Borghans et al. (2010), and Benítez-Silva et al. (2010).
} 
Barankay, I., and B. Lockwood, 2007, Decentralization and the productive efficiency of government: Evidence from Swiss cantons, Journal of Public Economics, vol. 91, pp. 1197-1218.

Bardhan, P. and D. Mookherjee, 2000, Capture and Governance at Local and National Levels, American Economic Review, Vol. 90, No. 2, pp. 135-139

Benítez-Silva, H., R. Disney and S. Jiménez-Martín, 2010, Disability, capacity for work and the business cycle: An international perspective, Economic Policy, vol. 25, no. 63, pp. 483-536.

Besley, T. and A. Case, 1995, Incumbent Behavior: Vote-Seeking, Tax-Setting, and Yardstick Competition, American Economic Review, vol. 85, no. 1, pp. 25-45.

Besley, T. and S. Coate, 2003, Centralized Versus Decentralized Provision of Local Public Goods, Journal of Public Economics, vol. 87, pp. 2611-2637.

Besley, T. and M. Smart, 2007, Fiscal restraints and voter welfare, Journal of Public Economics, vol. 91, no. 34, pp. 755-773.

Black, D., K. Daniel and S. Sanders, 2002, The Impact of Economic Conditions on Participation in Disability Programs: Evidence from the Coal Boom and Bust, American Economic Review, vol. 92, no. 1, pp. 27-50.

Boadway, R. and A. Shah, 2009, Fiscal Federalism, Cambridge University Press.

Borghans, L., A. Gielen, and E. Luttmer, 2010, Social Support Shopping: Evidence from a Regression Discontinuity in Disability Insurance Reform, IZA Discussion Paper 5412.

Bos, F., 2010, Fiscal decentralisation in the Netherlands; History, current practice and economic theory, CPB Document 214, CPB Netherlands Bureau for Economic Policy Analysis.

Chamberlain, 1984, Panel data, in: Z. Griliches and M. Intriligator (eds.), Handbook of Econometrics, Vol. 2, Amsterdam, North-Holland, ch. 22, pp. 1247-1318.

Cremer, J., A. Estache, and P. Seabright, 1996, Decentralizing Public Services: What Can We Learn from the Theory of the Firm, Revue d'Economie Politique, vol. 106, pp. 37-60.

Dafflon, 2008, The assignment of functions to decentralized government: from theory to practice, in: E. Ahmad and G. Brosio, Handbook of Fiscal Federalism, Edward Elgar, Cheltenham.

van Es, F., 2010, Invloed WWB op gebruik bijstand, CPB Document 209, CPB Netherlands Bureau for Economic Policy Analysis.

Hassink, W., J. van Ours and G. Ridder, 1997, Dismissal Through Disability, De Economist, vol. 145, no. 1, pp. $29-46$. 
Keen, M., 1998, Vertical Tax Externalities in the Theory of Fiscal Federalism, IMF Staff Papers, Vol. 45, No. 3, pp. 454-485.

Koning, P. and D. van Vuuren, 2010, Disability Insurance and Unemployment Insurance As Substitute Pathways, Applied Economics, vol. 42, no. 5, pp. 575-588.

Lockwood, B., 2002, Distributive Politics and the Costs of Centralization, Review of Economic Studies, vol. 69, pp. 313-337.

Moulton, B., 1990, An Illustration of a Pitfall in Estimating the Effects of Aggregate Variables on Micro Units, Review of Economics and Statistics, vol. 72, no. 2, pp. 334-338.

Seabright, P., 1996, Accountability and decentralization in government: an incomplete contracts model, European Economic Review, vol. 40, pp. 61-91.

Shleifer, A., 1985, A theory of yardstick competition, Rand Journal of Economics, vol. 16, 319-327.

van Sonsbeek, J., 2011, Microsimulation as a Decision Making Tool in Social Security Policy, PhD Thesis, Vrije Universiteit Amsterdam.

UWV, 2007, De groei van de Wajonginstroom, UWV Kenniscahier 07-01.

Westerhout, E., 2001, Disability Risk, Disability Benefits, and Equilibrium Unemployment, International Tax and Public Finance, vol. 8, nr. 3, pp. 219-244 


\section{Appendix A: Restrictions on the reduced form model}

Writing out the covariance matrix of the error terms in equation (4.4)-(4.6) as:

$\Sigma_{0}=\left(\begin{array}{ccc}\sigma_{s}^{2} & \rho_{s f, 0} \sigma_{s} \sigma_{f} & \rho_{s d, 0} \sigma_{s} \sigma_{d} \\ \rho_{s f, 0} \sigma_{s} \sigma_{f} & \sigma_{f}^{2} & \rho_{f d, 0} \sigma_{f} \sigma_{d} \\ \rho_{s d, 0} \sigma_{s} \sigma_{d} & \rho_{f d, 0} \sigma_{f} \sigma_{d} & \sigma_{d}^{2}\end{array}\right)$

where $s, f$ and $d$ subscripts again correspond to SA inflow, SA outflow and DI inflow respectively, and writing out the covariance matrix corresponding to (4.7)-(4.9) as:

$\Sigma=\left(\begin{array}{ccc}\tau_{s}^{2} & \rho_{s f} \tau_{s} \tau_{f} & \rho_{s d} \tau_{s} \tau_{d} \\ \rho_{s f} \tau_{s} \tau_{f} & \tau_{f}^{2} & \rho_{f d} \tau_{f} \tau_{d} \\ \rho_{s d} \tau_{s} \tau_{d} & \rho_{f d} \tau_{f} \tau_{d} & \tau_{d}^{2}\end{array}\right)$

we obtain the following set of restrictions on the parameters of the reduced-form model in terms of the parameters of the structural model:

$$
\begin{aligned}
& \gamma_{0 s}=1-\lambda \beta_{0 s}, \\
& \gamma_{b s}=1-\lambda \beta_{b s}, \\
& \gamma_{0 f}=1+\mu \beta_{0 f}, \\
& \gamma_{b f}=1+\mu \beta_{b f}, \\
& \gamma_{0 d}=\beta_{0 d}+\lambda \beta_{0 s}+\mu \beta_{0 f}, \\
& \gamma_{b d}=\lambda \beta_{b s}+\mu \beta_{b f}, \\
& \tau_{s}^{2}=1-\lambda{ }^{2} \sigma_{s}^{2}, \\
& \tau_{f}^{2}=1+\mu^{2} \sigma_{f}^{2}, \\
& \tau_{d}^{2}=\sigma_{d}^{2}+\lambda^{2} \sigma_{s}^{2}+\mu^{2} \sigma_{f}^{2}+2 \mu \rho_{f d, 0} \sigma_{f} \sigma_{d}+2 \lambda \rho_{s d, 0} \sigma_{s} \sigma_{d}+2 \lambda \mu \rho_{s f, 0} \sigma_{s} \sigma_{f}, \\
& \rho_{s f} \tau_{s} \tau_{f}=1-\lambda \quad 1+\mu \rho_{s f, 0} \sigma_{s} \sigma_{f}, \\
& \rho_{s d} \tau_{s} \tau_{d}=1-\lambda \rho_{s d, 0} \sigma_{s} \sigma_{d}+\lambda 1-\lambda \sigma_{s}^{2}+\mu 1-\lambda \rho_{s f, 0} \sigma_{s} \sigma_{f}, \\
& \rho_{f d} \tau_{f} \tau_{d}=1+\mu \rho_{f d, 0} \sigma_{f} \sigma_{d}+\lambda 1+\mu \rho_{s f, 0} \sigma_{s} \sigma_{f}+\mu 1+\mu \sigma_{f}^{2}
\end{aligned}
$$

as imposed by (4.1)-(4.3). The above set of equations is represented by $g(\theta)$ in Eq. (4.10) and (4.11).

\section{Appendix B: The fixed effects model}

Formally, assuming an unobserved disability risk factor denoted by $x_{u d}$ and using index $t$ for the year of observation and index $i$ for the municipality, our DI inflow equation (4.9) becomes:

$$
D_{i t}=x_{0 d, i t} \gamma_{0 d, t}+x_{b d, i t} \gamma_{b d, t}+x_{u d, i t} \gamma_{u d, t}+v_{d, i t}
$$

in which case the estimate of $\gamma_{b d, t}$, the effect of a variable of interest in a cross-section estimation (say the effect of $\mathrm{SA}_{-1}$ ), will be

$$
\hat{\gamma}_{b d, t}=\gamma_{b d, t}+\frac{\operatorname{cov}_{i}\left(x_{b d, i t}, x_{u d, i t} \gamma_{u d, t}\right)}{\operatorname{var}_{i}\left(x_{b d, i t}\right)}
$$


where the second term on the right-hand side is the bias due to unobserved heterogeneity, and the (co)variances are between municipalities. As explained in Section 5.1, such bias is unlikely to be substantial in our case, given the magnitude and significance of the effect of $\mathrm{SA}_{-1}$ relative to the effects of the most obvious disability risk factors and of the other control variables. It is, however, possible to make a stronger statement. The conventional way to address unobserved heterogeneity is to assume that the unobserved component of municipality heterogeneity is constant over time:

$x_{u d, i t} \gamma_{u d, t}=c_{i}$

and to estimate a corresponding "fixed effects" model based on within-municipality variability, e.g.,

$D_{i t}-\overline{D_{i}}=\left(x_{0 d, i t}-\bar{x}_{0 d, i}\right) \gamma_{0 d}+\left(x_{b d, i t}-\bar{x}_{b d, i}\right) \gamma_{b d}+v_{d, i t}$

where bars indicate averages over the time dimension of the panel. The unobserved component of municipality heterogeneity has dropped out of the equation under the assumption (B.3). Note that assumption (B.3) is quite strong. In particular, omitted-variables bias may still occur in a fixed-effects model if only the following, slightly weaker statement holds true:

$$
E\left[x_{u d, i t} \gamma_{u d, t}\right]=c_{i}
$$

where $E$ indicates the expectation value, since then in general

$$
\frac{\operatorname{cov}\left[x_{b d, i t}-\bar{x}_{b d, i}, x_{u d, i t} \gamma_{u d, t}-c_{i}\right]}{\operatorname{var}\left(x_{b d, i t}-\bar{x}_{b d, i}\right)} \neq 0
$$

which is the bias in coefficient $\gamma_{b d}$ due to unobserved variable $x_{u d}$. This term remains unequal to zero in the limit $T \rightarrow \infty$ where $T$ is the baseline of panel dimension $t$.

In Section 5.2, we assume "fixed effects" in the sense that

$$
\frac{\operatorname{cov}_{i}\left(x_{b d, i t}, x_{u d, i t} \gamma_{u d, t}\right)}{\operatorname{var}_{i}\left(x_{b d, i t}\right)}=\text { constant }
$$

where the (co)variances are between municipalities. In case of no serial correlation of the errors, or in the limit $T \rightarrow \infty$, this "fixed effects" assumption can in fact be weakened:

$$
E\left[\frac{\operatorname{cov}_{i}\left(x_{b d, i t}, x_{u d, i t} \gamma_{u d, t}\right)}{\operatorname{var}_{i}\left(x_{b d, i t}\right)}\right]=\text { constant }
$$

in contrast with the classical assumption (B.3). 
Appendix C: Estimation results in tabular form

Table C.1 Reduced-form cross-section estimates (x100), SA inflow, SA outflow, and DI inflow equations

(top to bottom). $\mathrm{C}^{*}$ : constants. $\mathrm{V}^{*}$ : covariance matrix $\Sigma\left(\mathrm{x} 10^{6}\right)$.

\begin{tabular}{|c|c|c|c|c|c|c|c|c|c|c|c|c|c|c|c|c|}
\hline & & 001 & & 2002 & & 2003 & & 2004 & & 2005 & & 2006 & & 2007 & & 2008 \\
\hline Immigran & .347 & .195) & .311 & 213) & .422 & .218) & .237 & 218) & .560 & 196) & -0.085 & .190) & -0.357 & .148) & 0.441 & \\
\hline LowSkill & 0.852 & .282) & 0.779 & 308) & 0.451 & .324) & 172 & 543) & .564 & $(0.451)$ & .527 & $.366)$ & 0.655 & 1) & 0.752 & .35 \\
\hline Disabled & 0.110 & $(0.550)$ & 0.845 & ) & 0.525 & $.593)$ & 0.681 & .621) & 1.524 & & 1.971 & $(0.606)$ & .802 & & 0.565 & . \\
\hline Urban & & & & & 0.008 & & & & & & & & & & & .032 \\
\hline Rented & 0.075 & $(0.135)$ & -0.074 & 142) & 0.071 & .149) & -0.036 & .149) & -0.429 & & -0.062 & $(0.1$ & 0.077 & & -0.393 & .153) \\
\hline SinglePa & 0.218 & (0.532) & -0.127 & $(0.558)$ & -0.489 & $(0.555)$ & -0.104 & (0.535) & -1.020 & $(0.483)$ & -1.267 & $(0.453)$ & -0.525 & $(0.347)$ & 0.362 & $(0.451)$ \\
\hline Age1819 & 0.617 & $(1.944)$ & 3.391 & .999) & 4.692 & $(2.082)$ & -0.296 & (2.071) & 2.429 & (1.968) & 1.638 & $(1.846)$ & -0.722 & $(1.427)$ & -1.240 & .800 \\
\hline Young & -0.495 & $(0.358)$ & -0.839 & .374) & -1.017 & $(0.384)$ & -0.188 & $(0.386)$ & 0.063 & & -0.612 & & -0.594 & & -0.294 & $(0.309)$ \\
\hline UIOut & -0.619 & 335) & 0.477 & .215) & -0.564 & $(0.331)$ & -1.145 & $(0.742)$ & 0.177 & & 0.550 & & 0.277 & & -0.184 & .322 \\
\hline UIOut-1 & 0.564 & $(0.323)$ & -0.878 & $(0.326)$ & 1.112 & $(0.289)$ & -0.245 & $(0.523)$ & -1.361 & $(0.736)$ & -0.266 & $(0.423)$ & 0.385 & $(0.388)$ & 0.221 & $(0.475)$ \\
\hline UIOut-2 & - & & 0.421 & $(0.292)$ & -0.678 & $(0.256)$ & 0.984 & $(0.400)$ & 0.096 & $(0.414)$ & -0.493 & $(0.528)$ & -0.103 & $(0.213)$ & 0.509 & $(0.502)$ \\
\hline GDP-1 & -0.009 & $(0.007)$ & -0.001 & $(0.005)$ & 0.009 & $(0.005)$ & 0.010 & $(0.009)$ & -0.019 & $(0.007)$ & -0.009 & $(0.006)$ & -0.015 & $(0.004)$ & -0.003 & $(0.007)$ \\
\hline GDP-2 & - & & -0.011 & $.006)$ & -0.013 & $(0.005)$ & 0.011 & $(0.007)$ & 0.002 & & -0.009 & & -0.011 & & & 006 \\
\hline SA-1 & 28.056 & (1.324) & 32.683 & (1.476) & 36.379 & (1.574) & 36.281 & (1.479) & 35.453 & (1.239) & 30.640 & (1.225) & 28.588 & (1.010) & 35.771 & (1.332) \\
\hline Immigran & -0.926 & $(0.187)$ & -0.716 & $(0.182)$ & -0.614 & $(0.169)$ & -0.864 & $(0.180)$ & -0.841 & $(0.158)$ & -0.638 & $(0.182)$ & -0.685 & $(0.163)$ & -0.716 & $(0.181)$ \\
\hline LowSkill & 0.784 & $(0.279)$ & 0.693 & $(0.266)$ & 0.523 & $(0.214)$ & 1.060 & $(0.368)$ & 0.345 & $(0.335)$ & 0.412 & $(0.283)$ & 0.359 & $(0.266)$ & 0.900 & $(0.364)$ \\
\hline Disabled & -0.044 & $(0.530)$ & 0.069 & .464) & -0.224 & $(0.458)$ & -0.569 & $(0.516)$ & -0.406 & $(0.474)$ & 0.497 & & -0.763 & & -1.047 & 10.0701 \\
\hline Urban & -0.018 & (0.029) & -0.008 & .029) & 0.056 & $(0.028)$ & 0.027 & & 0.013 & & 0.034 & & 0.025 & & & 030 \\
\hline Rented & 0.070 & $(0.130)$ & -0.065 & $(0.121)$ & -0.067 & $(0.114)$ & -0.089 & $(0.124)$ & -0.203 & $(0.107)$ & -0.261 & (0.129) & -0.066 & $(0.132)$ & -0.253 & $(0.147)$ \\
\hline SinglePa & 0.247 & $(0.509)$ & 0.203 & $(0.473)$ & -0.452 & $(0.427)$ & -0.144 & $(0.444)$ & -0.585 & $(0.388)$ & -0.253 & $(0.436)$ & -0.375 & $(0.384)$ & 0.480 & $(0.434)$ \\
\hline Age1819 & 1.536 & $(1.856)$ & 1.837 & .703) & 1.241 & (1.601) & -2.916 & (1.717) & -0.762 & $(1.574)$ & -1.173 & (1.779) & -1.551 & (1.580) & -4.155 & (1.731) \\
\hline Young & -0.691 & & & & -0.880 & & 0.190 & & & & & & & & & \\
\hline UlOut & -0.312 & $(0.330)$ & 0.435 & $(0.186)$ & -0.285 & (0.219) & -1.129 & $(0.503)$ & 0.168 & $(0.3$ & 0.253 & $(0.3$ & 0.266 & & -0.092 & $(0.327)$ \\
\hline UIOut-1 & 0.232 & $(0.318)$ & -0.599 & $(0.281)$ & 0.628 & $(0.192)$ & -0.111 & $(0.354)$ & -1.100 & $(0.546)$ & -0.391 & $(0.327)$ & 0.079 & (0.4 & 0.075 & $(0.485)$ \\
\hline UIOut-2 & - & & 0.154 & $(0.251)$ & -0.401 & $(0.169)$ & 0.778 & $(0.271)$ & 0.400 & $(0.307)$ & -0.123 & $(0.409)$ & -0.115 & $(0.24$ & 0.264 & (0.510) \\
\hline GDP-1 & -0.012 & $(0.006)$ & -0.008 & .004) & 0.008 & (0.003) & 0.008 & & -0.013 & & $-0 . C$ & & 12 & & & 007) \\
\hline GDP-2 & - & & -0.014 & .005) & -0.004 & $(0.003)$ & 0.003 & & 0.003 & & & & -0.0 & & & .006 \\
\hline SA-1 & .263 & (1.262) & 34.293 & (1.252) & 33.132 & (1.208) & 34.396 & (1.230) & 37.028 & (0.995) & 37.959 & (1.179) & 38.848 & & 38.093 & $(1.283)$ \\
\hline Immigran & -0.124 & $(0.046)$ & -0.123 & $(0.045)$ & -0.182 & $(0.048)$ & -0.155 & $(0.046)$ & -0.061 & $(0.050)$ & -0.111 & $(0.056)$ & -0.265 & $(0.061)$ & -0.191 & $(0.065)$ \\
\hline wSkill & -0.014 & .049) & & .065) & -0.038 & .067) & 0.052 & & -0.151 & & -0.075 & & -0.064 & & & 153) \\
\hline Disabled & & & & & & & & & & & & & & & & \\
\hline Urban & -0.016 & $(0.008)$ & -0.001 & $(0.007)$ & 0.001 & (0.008) & 0.011 & $(0.008)$ & 0.008 & & 0.002 & & 0.021 & & & $(0.011$ \\
\hline ented & 0.038 & $(0.032)$ & 0.024 & $(0.030)$ & -0.024 & $(0.033)$ & 0.038 & $(0.032)$ & 0.022 & $(0.034)$ & 0.090 & $(0.040)$ & 0.153 & $(0.050)$ & 0.058 & $(0.053)$ \\
\hline SinglePa & 054 & 123) & 27 & 18) & 075 & .122) & 008 & & -0.336 & & -0.535 & & -0.409 & & .322 & .155 \\
\hline Age1819 & & & & & & & & & & & & & & & & \\
\hline Young & -0.150 & $(0.083)$ & -0.164 & .079) & -0.091 & $(0.085)$ & -0.182 & & -0.012 & & -0.152 & & -0.147 & & & $(0.106$ \\
\hline UIOut & -0.054 & $(0.058)$ & 0.109 & $(0.046)$ & -0.119 & $(0.068)$ & 0.095 & $(0.119)$ & 0.153 & $(0.083)$ & -0.088 & $(0.120)$ & 0.001 & $(0.153)$ & -0.036 & $(0.137)$ \\
\hline UIOut-1 & 103 & $(0.056)$ & .086 & (0.069) & 141 & $(0.059)$ & -0.148 & $(0.085)$ & 0.172 & $(0.12$ & 0.275 & $(0.125)$ & -0.097 & $(0.19$ & 0.012 & $(0.205)$ \\
\hline UIOut-2 & - & - & 0.068 & $(0.062)$ & -0.016 & $(0.005)$ & & & -0.068 & & 0.008 & & & & 0.075 & $(0.214$ \\
\hline & -0.002 & $(0.001)$ & & & & & & & & & & & & & & \\
\hline GDP-2 & - & - & 0.001 & $(0.001)$ & 0.000 & $(0.001)$ & 0.000 & $(0.001)$ & 0.000 & (0.001) & 0.001 & $(0.00$ & 0.001 & $(0.00$ & 0.002 & $(0.003)$ \\
\hline-1 & & & & & & & 1.096 & $(0.327)$ & 1.954 & & 3.023 & & 3.765 & & 45 & $(0.458)$ \\
\hline C_S & -0.014 & $(0.151)$ & -0.120 & $(0.163)$ & -0.005 & $(0.168)$ & -0.096 & $(0.172)$ & 0.577 & $(0.166)$ & 0.092 & $(0.196)$ & -0.248 & $(0.164)$ & -0.227 & $(0.201)$ \\
\hline C_F & & $(0.143)$ & & .139) & 0.0 & $(0.1<0)$ & & & 0.473 & & & & 0.054 & & -0.030 & (0.193 \\
\hline C_D & -0.056 & $(0.035)$ & -0.089 & $(0.035)$ & -0.030 & $(0.036)$ & -0.142 & $(0.037)$ & -0.077 & & -0.077 & & -0.029 & & -0.067 & $(0.069)$ \\
\hline & & $(0.128)$ & 1.363 & & 1.259 & & 1.534 & $(0.126)$ & 0.838 & $(0.09$ & 1.132 & & 0.682 & $(0.072$ & 1.028 & D.102) \\
\hline V_SD & 0.061 & $(0.024)$ & 033 & $(0.024)$ & 0.0 & $(0.028)$ & 0.007 & $(0.026)$ & 0.070 & $(0.026)$ & 0.096 & $(0.0$ & 0.095 & $(0.02$ & 0.047 & $(0.032)$ \\
\hline V_FD & 0.055 & $(0.023)$ & 0.031 & $(0.020)$ & 0.023 & (0.021) & -0.005 & $(0.022)$ & 0.030 & $(0.021)$ & 0.053 & $(0.028)$ & 0.147 & $(0.028)$ & 0.029 & $(0.031)$ \\
\hline V_S & 2.203 & $(0.149)$ & & & & & & & & & & & 1.221 & & 1.944 & $(0.131)$ \\
\hline$V_{-} F$ & 2.012 & $(0.136)$ & 1.686 & & 1.549 & $(0.104)$ & 1.794 & $(0.121)$ & 1.373 & & 1.895 & & 1.492 & & 1.797 & $(0.121)$ \\
\hline V_D & 0.116 & $(0.008)$ & 0.105 & $(0.007)$ & 0.127 & (0.009) & 0.116 & $(0.008)$ & 0.138 & $(0.009)$ & 0.182 & $(0.012)$ & 0.211 & $(0.014)$ & 0.230 & $(0.016)$ \\
\hline
\end{tabular}


Table C.2 Structural-form cross-section estimates (x100), SA inflow, SA outflow, and DI inflow equations

(top to bottom), $\lambda$ mechanism. $C^{*}$ : constants. $V^{*}$ : covariance matrix $\Sigma_{0}\left(\times 10^{6}\right)$.

\begin{tabular}{|c|c|c|c|c|c|c|c|c|c|c|c|c|c|c|c|c|}
\hline & & 2001 & & 2002 & & 2003 & & 2004 & & 2005 & & 2006 & & 2007 & & 20 \\
\hline Immigran & -0.358 & $(0.201)$ & 0.319 & $(0.219)$ & -0.438 & $(0.227)$ & -1.274 & $(0.224)$ & -0.590 & $(0.207)$ & -0.093 & $(0.208)$ & -0.404 & $(0.167)$ & -0.481 & $(0.206)$ \\
\hline LowSkill & 0.880 & ..292) & 0.799 & $(0.316)$ & 0.469 & .337) & 1.208 & $(0.560)$ & 0.595 & $(0.476)$ & 0.578 & & 0.741 & & 0.820 & \\
\hline Disabled & 0.113 & $(0.568)$ & 0.866 & & 0.545 & & 0.702 & & & & & & -0.908 & & & \\
\hline Urban & 0.000 & $(0.030)$ & 0.010 & $(0.034)$ & 0.009 & $(0.038)$ & 0.054 & (0.038) & -0.013 & $(0.034)$ & 0.022 & $(0.035)$ & 0.023 & & 0.0 & 34) \\
\hline Rented & 0.078 & $(0.140)$ & -0.076 & $(0.146)$ & 0.074 & $(0.154)$ & -0.037 & $(0.154)$ & -0.453 & $(0.140)$ & -0.068 & $(0.147)$ & 0.087 & $(0.135)$ & -0.428 & $(0.167)$ \\
\hline SinglePa & 0.225 & $(0.549)$ & -0.131 & $(0.572)$ & -0.507 & $(0.576)$ & -0.108 & $(0.551)$ & -1.076 & $(0.509)$ & -1.392 & $(0.497)$ & -0.594 & $(0.392)$ & -0.395 & .491) \\
\hline Age1819 & 0.637 & $(2.008)$ & 3.478 & $(2.051)$ & 4.869 & $(2.162)$ & -0.305 & & 2.563 & $(2.077)$ & 1.799 & & -0.818 & $(1.615)$ & -1.352 & $(1.963)$ \\
\hline Young & -0.512 & $(0.370)$ & -0.861 & $(0.384)$ & -1.056 & $(0.399)$ & -0.193 & $(0.398)$ & 0.067 & $(0.380)$ & -0.673 & $(0.373)$ & -0.672 & $(0.278)$ & -0.3 & $(0.337)$ \\
\hline UlOut & -0.639 & $(0.346)$ & 0.489 & $(0.221)$ & -0.585 & (0.344) & -1.180 & $(0.764)$ & 0.187 & $(0.506)$ & 0.604 & $(0.437)$ & 0.313 & $(0.346)$ & -0.201 & $(0.351)$ \\
\hline UIOut-1 & 0.583 & $(0.334)$ & -0.900 & $(0.335)$ & 1.154 & $(0.301)$ & -0.253 & $(0.538)$ & -1.436 & $(0.777)$ & -0.292 & $(0.464)$ & 0.435 & $(0.439)$ & 0.241 & $.518)$ \\
\hline UIOut-2 & 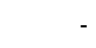 & - & 0.432 & $(0.299)$ & -0.703 & $(0.266)$ & 1.013 & $(0.413)$ & 0.101 & $(0.437)$ & -0.542 & $(0.580)$ & -0.117 & $(0.241)$ & 0.555 & $(0.547)$ \\
\hline GDP-1 & -0.009 & $(0.007)$ & -0.001 & $(0.005)$ & 0.009 & $(0.005)$ & 0.010 & $(0.009)$ & -0.020 & $(0.007)$ & -0.010 & $(0.007)$ & -0.016 & & -0.003 & $(0.008)$ \\
\hline GDP-2 & & - & -0.011 & $(0.006)$ & -0.014 & $(0.005)$ & 0.012 & $(0.007)$ & 0.003 & $(0.008)$ & -0.010 & $(0.006)$ & -0.013 & $(0.005)$ & -0.009 & $(0.007)$ \\
\hline SA-1 & 28.972 & (1.394) & 33.519 & (1.528) & 37.755 & (1.642) & 37.377 & (1.518) & 37.408 & (1.317) & 33.663 & (1.331) & 32.353 & $(1.163)$ & 39.016 & (1.439) \\
\hline Immigran & -0.926 & $(0.187)$ & -0.716 & $(0.182)$ & -0.614 & $(0.169)$ & -0.864 & $(0.180)$ & -0.841 & $(0.158)$ & -0.638 & $(0.182)$ & -0.685 & $(0.163)$ & -0.716 & $(0.181)$ \\
\hline LowSkill & 0.784 & $(0.279)$ & 0.693 & $(0.266)$ & 0.523 & $(0.214)$ & 1.060 & $(0.368)$ & 0.345 & $(0.335)$ & 0.412 & $(0.283)$ & 0.359 & & 0.900 & $(0.364)$ \\
\hline Disabled & -0.044 & $(0.5$ & 0.069 & $(0.464)$ & -0.224 & $(0.458)$ & -0.569 & & -0.406 & $(0.4$ & 0.497 & & -0.763 & & & \\
\hline Urban & -0.018 & $(0.029)$ & -0.008 & $(0.029)$ & 0.056 & $(0.028)$ & 0.027 & $(0.030)$ & 0.013 & $(0.026)$ & 0.034 & $(0.030)$ & 0.025 & $(0.027)$ & -0.006 & $(0.030)$ \\
\hline Rented & 0.070 & $(0.130)$ & -0.065 & $(0.121)$ & -0.067 & $(0.114)$ & -0.089 & $(0.124)$ & -0.203 & $(0.107)$ & -0.261 & $(0.129)$ & -0.066 & $(0.132)$ & -0.253 & $(0.147)$ \\
\hline SinglePa & 0.247 & $(0.509)$ & 0.203 & $(0.473)$ & -0.452 & $(0.427)$ & -0.144 & $(0.444)$ & -0.585 & $(0.388)$ & -0.253 & $(0.436)$ & -0.375 & $(0.3$ & 0.480 & $(0.434)$ \\
\hline Age1819 & 1.536 & 56) & 1.837 & $(1.703)$ & 1.241 & .601) & -2.916 & & -0.762 & & & & & & & \\
\hline Young & -0.691 & $(0.344)$ & -1.046 & $(0.319)$ & -0.880 & $(0.297)$ & 0.190 & $(0.321)$ & -0.253 & $(0.287)$ & -0.039 & $(0.327)$ & -0.390 & $(0.2$ & & 297) \\
\hline UIOut & -0.312 & $(0.330)$ & 0.435 & $(0.186)$ & -0.285 & $(0.219)$ & -1.129 & $(0.503)$ & 0.168 & $(0.356)$ & 0.253 & $(0.307)$ & 0.266 & $(0.349)$ & -0.092 & $(0.327)$ \\
\hline UIOut-1 & 0.232 & $(0.318)$ & -0.599 & $(0.281)$ & 0.628 & $(0.192)$ & -0.111 & $(0.354)$ & -1.100 & $(0.546)$ & -0.391 & $(0.327)$ & 0.079 & $(0.443)$ & 0.075 & $(0.485)$ \\
\hline UIOut-2 & - & - & 0.154 & $(0.251)$ & -0.401 & $0.169)$ & 0.778 & $(0.271)$ & 0.400 & $(0.3$ & -0.123 & & -0.115 & & 264 & 510) \\
\hline GDP-1 & -0.012 & & -0.008 & $(0.004)$ & 0.008 & $(0.003)$ & 0.008 & $(0.006)$ & -0.013 & $(0.005)$ & -0.008 & & -0.012 & & & $.007)$ \\
\hline GDP-2 & - & - & -0.014 & $(0.005)$ & -0.004 & $(0.003)$ & 0.003 & $(0.005)$ & 0.003 & $(0.005)$ & -0.006 & $(0.005)$ & -0.008 & $(0.005)$ & -0.010 & $(0.006)$ \\
\hline SA-1 & 35.263 & $(1.262)$ & 34.293 & (1.252) & 33.132 & (1.208) & 34.396 & $(1.230)$ & 37.028 & (0.995) & 37.959 & (1.179) & 38.848 & $(1.116)$ & 38.093 & (1.283) \\
\hline Immigran & -0.113 & $(0.045)$ & -0.115 & $(0.045)$ & -0.166 & $(0.048)$ & -0.118 & $(0.048)$ & -0.030 & $(0.050)$ & -0.103 & $(0.056)$ & -0.218 & $(0.0$ & -0.151 & .066) \\
\hline LowSkill & -0.042 & $(0.052)$ & -0.010 & $(0.068)$ & -0.055 & $(0.068)$ & & & & $(0.080)$ & & & & & & \\
\hline Disabled & 0.607 & $(0.122)$ & 0.465 & (0.119) & 0.554 & $(0.133)$ & 0.712 & $(0.135)$ & 0.645 & $(0.155)$ & 1.051 & $(0.189)$ & 1.225 & $(0.205)$ & 1.511 & $(0.245)$ \\
\hline Urban & -0.016 & $(0.007)$ & -0.002 & $(0.007)$ & 0.001 & $(0.008)$ & 0.009 & $(0.008)$ & 0.009 & $(0.008)$ & 0.000 & $(0.009)$ & 0.018 & $(0.010)$ & 0.017 & $(0.011)$ \\
\hline Rented & 0.036 & $(0.031)$ & 0.026 & $(0.030)$ & -0.027 & $(0.033)$ & 0.039 & $(0.032)$ & 0.046 & $(0.033)$ & 0.096 & $(0.040)$ & 0.143 & $(0.049)$ & 0.094 & (0.053) \\
\hline SinglePa & 0.047 & $(0.124)$ & 0.130 & (0.1) & 0.093 & $(0.10)$ & 0.011 & & -0.280 & $(0.117)$ & -0.410 & & -0.340 & & & $(0.155)$ \\
\hline Age1819 & 1.801 & $(0.445)$ & 1.566 & 101301 & 1.604 & $(0.468)$ & 2.152 & & 0.608 & $(0.499)$ & 1.521 & & 1.863 & & & (0.628) \\
\hline Young & -0.134 & $(0.082)$ & -0.143 & $(0.079)$ & -0.053 & $(0.084)$ & -0.176 & $(0.081)$ & -0.015 & $(0.088)$ & -0.092 & $(0.100)$ & -0.069 & $(0.100)$ & 0.132 & $(0.107)$ \\
\hline UlOut & -0.034 & $(0.058)$ & 0.097 & $(0.046)$ & -0.098 & $(0.070)$ & 0.129 & $(0.123)$ & 0.144 & $(0.084)$ & -0.142 & $(0.122)$ & -0.035 & $(0.153)$ & -0.020 & $(0.138)$ \\
\hline UIOut-1 & 0.085 & $(0.056)$ & -0.063 & $(0.070)$ & 0.099 & $(0.062)$ & -0.141 & $(0.087)$ & 0.247 & $(0.129)$ & 0.301 & $(0.126)$ & -0.148 & & -0.008 & $(0.206)$ \\
\hline UIOut-2 & & & 0.057 & & 0.010 & & 0.151 & & -0.073 & $(0.072)$ & & & & & & \\
\hline GDP-1 & -0.001 & $(0.001)$ & 0.000 & $(0.001)$ & 0.000 & $(0.001)$ & 0.002 & $(0.001)$ & 0.003 & $(0.001)$ & 0.001 & $(0.002)$ & 0.005 & $(0.002)$ & -0.004 & $(0.003)$ \\
\hline GDP-2 & - & - & 0.001 & $(0.001)$ & 0.000 & $(0.001)$ & 0.000 & $(0.001)$ & 0.000 & $(0.001)$ & 0.002 & $(0.002)$ & 0.003 & $(0.002)$ & 0.002 & $(0.003)$ \\
\hline SA-1 & 0.032 & $(0.010)$ & 0.025 & $(0.009)$ & 0.036 & $(0.009)$ & 0.029 & $(0.009)$ & 0.052 & $(0.008)$ & 0.090 & $(0.010)$ & 0.116 & $(0.011)$ & 0.083 & $(0.011)$ \\
\hline C_S & -0.014 & $(0.156)$ & -0.123 & $(0.168)$ & -0.005 & $(0.174)$ & -0.099 & $(0.177)$ & 0.609 & $(0.175)$ & 0.101 & $(0.215)$ & -0.281 & $(0.185)$ & -0.248 & $(0.220)$ \\
\hline C_F & 0.033 & $(0.143)$ & 0.061 & $(0.139)$ & 0.091 & $(0.126)$ & 0.083 & $(0.143)$ & 0.473 & $(0.133)$ & 0.283 & & 0.054 & & -0.030 & $(0.193)$ \\
\hline C_D & -0.055 & $(0.034)$ & -0.085 & $(0.035)$ & -0.030 & $(0.036)$ & -0.139 & $(0.037)$ & -0.109 & $(0.041)$ & -0.086 & $(0.058)$ & 0.004 & $(0.069)$ & -0.047 & $(0.072)$ \\
\hline V_SF & 1.703 & $(0.133)$ & 1.397 & $(0.118)$ & 1.307 & $(0.118)$ & 1.580 & $(0.131)$ & 0.884 & $(0.096)$ & 1.244 & $(0.120)$ & 0.772 & $(0.082)$ & 1.121 & $(0.112)$ \\
\hline V_SD & -0.011 & $(0.035)$ & -0.027 & $(0.033)$ & -0.051 & $(0.039)$ & -0.074 & $(0.037)$ & -0.050 & $(0.034)$ & -0.116 & $(0.043)$ & -0.074 & $(0.035)$ & -0.142 & $(0.046)$ \\
\hline V_FD & 0.002 & $(0.029)$ & -0.004 & $(0.024)$ & -0.024 & $(0.024)$ & -0.052 & $(0.026)$ & -0.017 & $(0.022)$ & -0.058 & $(0.031)$ & 0.057 & $(0.029)$ & -0.065 & $(0.034)$ \\
\hline V_S & 2.349 & $(0.166)$ & 2.444 & $(0.171)$ & 2.797 & $(0.195)$ & 2.765 & $(0.193)$ & 2.367 & $(0.165)$ & 2.466 & $(0.175)$ & 1.563 & $(0.113)$ & 2.313 & $(0.165)$ \\
\hline V_F & 2.012 & $(0.136)$ & 1.686 & $(0.11$ & 1.549 & $(0.104)$ & 1.794 & $(0.121)$ & 1.373 & $(0.093)$ & 1.895 & $(0.128)$ & 1.492 & $(0.101)$ & 1.797 & $(0.121)$ \\
\hline V_D & 0.115 & $(0.008)$ & 0.105 & $(0.007)$ & 0.127 & $(0.009)$ & 0.118 & $(0.008)$ & 0.137 & $(0.009)$ & 0.183 & $(0.013)$ & 0.207 & $(0.014)$ & 0.238 & $(0.016)$ \\
\hline
\end{tabular}


Table C.3 Structural-form cross-section estimates (x100), SA inflow, SA outflow, and DI inflow equations

(top to bottom), $\mu$ mechanism. $C^{*}$ : constants. $V^{*}$ : covariance matrix $\Sigma_{0}\left(\times 10^{6}\right)$.

\begin{tabular}{|c|c|c|c|c|c|c|c|c|c|c|c|c|c|c|c|c|}
\hline & & 2001 & & 2002 & & 2003 & & 2004 & & 2005 & & 2006 & & 2007 & & 2008 \\
\hline Immigran & -0.347 & $(0.195)$ & -0.311 & $(0.213)$ & -0.422 & $(0.218)$ & -1.237 & $(0.218)$ & -0.560 & $(0.196)$ & -0.085 & $(0.190)$ & -0.357 & $(0.148)$ & -0.441 & \\
\hline LowSkill & 0.852 & $(0.282)$ & 0.779 & $(0.308)$ & 0.451 & $(0.324)$ & 1.172 & $(0.543)$ & 0.564 & $(0.451)$ & 0.527 & $(0.366)$ & 0.655 & $(0.231)$ & 0.752 & $(0.359)$ \\
\hline Disabled & 0.110 & $(0.550)$ & 0.845 & $(0.546)$ & 0.525 & $(0.593)$ & 0.681 & $(0.621)$ & 1.524 & $(0.590)$ & 1.971 & $(0.606)$ & -0.802 & $(0.505)$ & 0.565 & $(0.697)$ \\
\hline Urban & 0.000 & $(0.029)$ & 0.010 & $(0.034)$ & 0.008 & $(0.036)$ & 0.053 & $(0.037)$ & -0.012 & $(0.033)$ & 0.020 & $(0.031)$ & 0.020 & $(0.025)$ & 0.021 & $(0.032)$ \\
\hline Rented & 0.075 & $(0.135)$ & -0.074 & $(0.142)$ & 0.071 & $(0.149)$ & -0.036 & $(0.149)$ & -0.429 & $(0.133)$ & -0.062 & $(0.134)$ & 0.077 & $(0.119)$ & -0.393 & $.153)$ \\
\hline SinglePa & 0.218 & $(0.532)$ & -0.127 & $(0.558)$ & -0.489 & $(0.555)$ & -0.104 & $(0.535)$ & -1.020 & & -1.267 & $(0.453)$ & -0.525 & & -0.362 & $(0.451)$ \\
\hline Age1819 & 0.617 & (1.944) & 3.391 & (1.999) & 4.692 & (2.082) & -0.296 & (2.071) & 2.429 & (1.968) & 1.638 & (1.846) & -0.722 & (1.427) & -1.240 & $(1.800)$ \\
\hline Young & -0.495 & $(0.358)$ & -0.839 & $(0.374)$ & -1.017 & $(0.384)$ & -0.188 & $(0.386)$ & 0.063 & $(0.360)$ & -0.612 & $(0.340)$ & -0.594 & $(0.246)$ & -0.294 & $(0.309)$ \\
\hline UIOut & -0.619 & $(0.335)$ & 0.477 & $(0.215)$ & -0.564 & $(0.331)$ & -1.145 & $(0.742)$ & 0.177 & $(0.479)$ & 0.550 & $(0.397)$ & 0.277 & $(0.306)$ & -0.184 & $(0.322)$ \\
\hline UIOut-1 & 0.564 & $(0.323)$ & -0.878 & $(0.326)$ & 1.112 & $(0.289)$ & -0.245 & $(0.523)$ & -1.361 & $(0.736)$ & -0.266 & $(0.423)$ & 0.385 & & 0.221 & $(0.475)$ \\
\hline UIOut-2 & - & & 0.421 & $(0.292)$ & -0.678 & $(0.256)$ & 0.984 & $(0.400)$ & 0.096 & $(0.414)$ & -0.493 & $(0.528)$ & -0.103 & & 0.509 & $(0.502)$ \\
\hline GDP-1 & -0.009 & $(0.007)$ & -0.001 & $(0.005)$ & 0.009 & $(0.005)$ & 0.010 & $(0.009)$ & -0.019 & $(0.007)$ & -0.009 & $(0.006)$ & -0.015 & $(0.004)$ & -0.003 & $(0.007)$ \\
\hline GDP-2 & - & & -0.011 & $(0.006)$ & -0.013 & $(0.005)$ & 0.011 & $(0.007)$ & 0.002 & $(0.007)$ & -0.009 & $(0.006)$ & -0.011 & $(0.004)$ & -0.008 & $(0.006)$ \\
\hline SA-1 & 28.056 & $(1.324)$ & 32.683 & (1.476) & 36.379 & (1.574) & 36.281 & (1.479) & 35.453 & (1.239) & 30.640 & (1.225) & 28.588 & $(1.010)$ & 35.771 & (1.332) \\
\hline Immigran & -0.902 & $(0.183)$ & -0.699 & $(0.177)$ & -0.588 & $(0.162)$ & -0.837 & $(0.175)$ & -0.797 & $(0.150)$ & -0.588 & $(0.168)$ & -0.619 & & -0.655 & $(0.166)$ \\
\hline LowSkill & 0.763 & $(0.272)$ & 0.676 & $(0.259)$ & 0.501 & $(0.205)$ & 1.026 & $(0.356)$ & 0.327 & $(0.317)$ & 0.380 & $(0.260)$ & 0.324 & (1) 24 & 0.823 & (0.333) \\
\hline Disabled & -0.043 & $(0.517)$ & 0.067 & $(0.453)$ & -0.215 & $(0.439)$ & -0.551 & $(0.500)$ & -0.385 & (0.449) & 0.458 & $(0.537)$ & -0.689 & $(0.504)$ & -0.958 & $(0.614)$ \\
\hline Urban & -0.017 & $(0.028)$ & -0.008 & $(0.028)$ & 0.054 & $(0.027)$ & 0.027 & (0.029) & 0.013 & $(0.025)$ & 0.031 & $(0.028)$ & 0.022 & $(0.025)$ & -0.006 & $(0.028)$ \\
\hline Rented & 0.068 & $(0.126)$ & -0.063 & $(0.118)$ & -0.064 & $(0.110)$ & -0.087 & $(0.120)$ & -0.192 & $(0.101)$ & -0.240 & $(0.119)$ & -0.059 & & -0.231 & $(0.135)$ \\
\hline SinglePa & 0.241 & $(0.496)$ & 0.198 & $(0.462)$ & -0.433 & & -0.139 & & -0.554 & & -0.233 & & -0.338 & & & $(0.397)$ \\
\hline Age1819 & 1.496 & $(1.808)$ & 1.792 & $(1.661)$ & 1.189 & (1.534) & -2.823 & (1.663) & -0.721 & (1.491) & -1.080 & (1.638) & -1.401 & (1.428) & -3.801 & (1.586) \\
\hline Young & -0.673 & $(0.335)$ & -1.021 & $(0.311)$ & -0.844 & $(0.285)$ & 0.184 & $(0.310)$ & -0.239 & $(0.272)$ & -0.036 & $(0.301)$ & -0.352 & $(0.246)$ & 0.197 & $(0.272)$ \\
\hline UlOut & -0.304 & $(0.322)$ & 0.425 & $(0.181)$ & -0.273 & $(0.210)$ & -1.093 & $(0.487)$ & 0.159 & $(0.338)$ & 0.233 & $(0.283)$ & 0.240 & $(0.315)$ & -0.084 & $(0.299)$ \\
\hline UIOut-1 & 0.226 & (.310) & -0.584 & & 0.602 & & -0.108 & & -1.042 & & -0.360 & & 0.071 & & & $(0.443)$ \\
\hline UIOut-2 & - & & 0.150 & $(0.245)$ & -0.384 & $(0.162)$ & 0.753 & $(0.263)$ & 0.379 & $(0.291)$ & -0.113 & $(0.376)$ & -0.104 & & 41 & $(0.467)$ \\
\hline GDP-1 & -0.012 & $(0.006)$ & -0.008 & $(0.004)$ & 0.008 & $(0.003)$ & 0.007 & $(0.006)$ & -0.013 & $(0.005)$ & -0.008 & $(0.005)$ & -0.011 & $(0.004)$ & -0.009 & $(0.007)$ \\
\hline GDP-2 & - & & -0.014 & $(0.005)$ & -0.004 & $(0.003)$ & 0.003 & $(0.005)$ & 0.003 & $(0.005)$ & -0.005 & $(0.004)$ & -0.007 & $(0.004)$ & -0.009 & $(0.006)$ \\
\hline SA-1 & 4.347 & $(1.263)$ & 33.457 & (1.269) & 1.757 & (1.238) & 33.300 & $(1.276)$ & 35.074 & & 34.936 & $(1.203)$ & 35.083 & (1. & 34.848 & (1.342) \\
\hline Immigran & -0.100 & $(0.046)$ & -0.106 & $(0.045)$ & -0.157 & $(0.049)$ & -0.128 & & -0.016 & & -0.061 & & & & & $(0.066)$ \\
\hline LowSkill & -0.034 & $(0.051)$ & -0.007 & $(0.067)$ & -0.059 & $(0.068)$ & 0.019 & $(0.093)$ & -0.169 & $(0.080)$ & -0.108 & $(0.112)$ & -0.098 & $(0.117)$ & -0.008 & $(0.156)$ \\
\hline Disabled & 0.612 & $(0.121)$ & 0.485 & $(0.116)$ & 0.583 & $(0.131)$ & 0.750 & $(0.131)$ & 0.750 & $(0.149)$ & 1.206 & $(0.184)$ & 1.193 & $(0.201)$ & 1.651 & $(0.239)$ \\
\hline Urban & -0.016 & $(0.008)$ & -0.001 & $(0.007)$ & -0.001 & $(0.008)$ & 0.010 & $(0.008)$ & 0.007 & $(0.00$ & -0.001 & $(0.009)$ & .018 & & .020 & $(0.011)$ \\
\hline Rented & & $(0.031)$ & & & -0.022 & & & & & & & & 0.159 & & & $(0.053)$ \\
\hline SinglePa & 0.048 & $(0.124)$ & 0.122 & $(0.119)$ & 0.094 & $(0.120)$ & 0.013 & $(0.126)$ & -0.306 & $(0.120)$ & -0.514 & $(0.135)$ & -0.373 & & -0.363 & $(0.160)$ \\
\hline Age1819 & 1.781 & $(0.447)$ & 1.608 & $(0.428)$ & 1.730 & $(0.462)$ & 2.236 & $(0.434)$ & 0.782 & $(0.497)$ & 1.776 & $(0.554)$ & 1.918 & $(0.571)$ & 2.084 & $(0.627)$ \\
\hline Young & -0.132 & $(0.082)$ & -0.139 & $(0.078)$ & -0.055 & $(0.084)$ & -0.188 & $(0.082)$ & 0.002 & $(0.088)$ & -0.149 & $(0.102)$ & -0.109 & $(0.098)$ & 0.087 & $(0.109)$ \\
\hline UIOut & -0.046 & $(0.058)$ & 0.099 & $(0.046)$ & -0.107 & $(0.069)$ & & & 0.144 & & -0.108 & & -0.024 & & -0.028 & $(0.139)$ \\
\hline UIOut-1 & 0.097 & $(0.056)$ & -0.071 & $(0.070)$ & 0.115 & $(0.061)$ & -0.144 & & & & 0.306 & & -0.105 & & & $(0.206)$ \\
\hline UIOut-2 & - & - & 0.064 & $(0.062)$ & 0.001 & $(0.053)$ & 0.156 & $(0.068)$ & -0.089 & $(0.072)$ & 0.018 & $(0.147)$ & 0.155 & $(0.107)$ & 0.052 & $(0.216)$ \\
\hline GDP-1 & -0.001 & $(0.001)$ & 0.000 & $(0.001)$ & 0.000 & $(0.001)$ & 0.002 & (0.001) & 0.003 & $(0.001)$ & 0.000 & $(0.002)$ & 0.005 & $(0.002)$ & -0.004 & $(0.003)$ \\
\hline GDP-2 & - & - & 0.001 & $(0.001)$ & 0.000 & $(0.001)$ & 0.000 & $(0.001)$ & 0.000 & $(0.001)$ & 0.001 & $(0.002)$ & 0.002 & $(0.002)$ & 0.002 & $(0.003)$ \\
\hline SA-1 & 0.027 & $(0.009)$ & 0.025 & $(0.01$ & 0.043 & & 0.033 & & 0.056 & & 0.087 & & 0.107 & & 0.093 & $(0.015)$ \\
\hline C_S & -0.014 & $(0.151)$ & -0.120 & $(0.163)$ & -0.005 & $(0.168)$ & -0.096 & $(0.172)$ & 0.577 & $(0.166$ & 0.092 & $(0.196)$ & -0.248 & & -0.227 & $(0.201)$ \\
\hline C_F & 0.032 & $(0.140)$ & 0.060 & $(0.136)$ & 0.087 & $(0.120)$ & 0.080 & $(0.138)$ & 0.448 & $(0.126)$ & 0.261 & $(0.174)$ & 0.049 & $(0.163)$ & -0.027 & $(0.177)$ \\
\hline C_D & -0.056 & $(0.034)$ & -0.090 & $(0.034)$ & -0.033 & $(0.036)$ & -0.144 & $(0.037)$ & -0.102 & $(0.041)$ & -0.100 & $(0.058)$ & -0.034 & $(0.066)$ & -0.065 & $(0.071)$ \\
\hline V_SF & 1.606 & $(0.125)$ & 1.329 & $(0.113)$ & 1.207 & $(0.109)$ & 1.485 & $(0.123)$ & 0.794 & $(0.086)$ & 1.042 & $(0.100)$ & 0.616 & $(0.066)$ & 0.940 & $(0.094)$ \\
\hline V_SD & 0.018 & $(0.028)$ & 0.000 & $(0.027)$ & -0.004 & $(0.031)$ & -0.042 & & 0.026 & $(0.027)$ & 0.006 & & 0.029 & & -0.041 & $(0.035)$ \\
\hline V_FD & 0.003 & $(0.028)$ & -0.010 & $(0.025)$ & -0.039 & $(0.025)$ & -0.061 & $(0.027)$ & -0.041 & $(0.023)$ & -0.090 & $(0.031)$ & 0.002 & $(0.027)$ & -0.114 & $(0.035)$ \\
\hline V_S & 2.203 & $(0.149)$ & 2.324 & $(0.15$ & 2.597 & $(0.175)$ & 2.605 & $(0.176)$ & 2.127 & $(0.143)$ & 2.043 & $(0.138)$ & 1.221 & $(0.082)$ & 1.944 & $(0.131)$ \\
\hline V_F & 1.909 & $(0.133)$ & 1.605 & $(0.112)$ & 1.423 & $(0.101)$ & 1.682 & $(0.118)$ & 1.232 & $(0.086)$ & 1.605 & $(0.113)$ & 1.217 & $(0.087)$ & 1.504 & $(0.109)$ \\
\hline V_D & 0.115 & $(0.008)$ & 0.105 & $(0.007)$ & 0.128 & $(0.009)$ & 0.118 & (0.008) & 0.139 & $(0.009)$ & 0.185 & $(0.013)$ & 0.197 & $(0.013)$ & 0.238 & $(0.016)$ \\
\hline
\end{tabular}


Table C.4 Reduced-form random-effects estimates (x100), SA inflow, SA outflow, and DI inflow equations

(top to bottom). $\mathrm{C}^{*}$ : constants. $\mathrm{V}^{*}$ : covariance matrix of idiosyncratic errors $\left(\times 10^{6}\right)$. $\mathrm{RAN}^{*}$ : random effects variance

$\left(\times 10^{6}\right) . \mathrm{RHO}^{*}$ : serial correlation.

\begin{tabular}{|c|c|c|c|c|c|c|c|c|c|c|c|c|c|c|c|c|}
\hline & & 2001 & & 2002 & & 2003 & & 2004 & & 2005 & & 2006 & & 2007 & & 2008 \\
\hline Immigran & 0.177 & $(0.151)$ & 0.034 & $(0.188)$ & -0.091 & $(0.173)$ & -0.476 & $(0.208)$ & -0.283 & $(0.177)$ & 0.194 & $(0.182)$ & -0.117 & $(0.117)$ & -0.110 & $(0.159)$ \\
\hline LowSkill & 0.366 & $(0.131)$ & 0.311 & $(0.189)$ & 0.026 & $(0.052)$ & -0.013 & $(0.109)$ & -0.030 & $(0.290)$ & 0.442 & $(0.181)$ & 0.406 & $(0.185)$ & 0.443 & $(0.173)$ \\
\hline Disabled & -0.303 & $(0.433)$ & 0.693 & $(0.503)$ & 0.836 & (0.522) & 1.645 & (0.579) & 0.783 & $(0.632)$ & 1.130 & $(0.573)$ & -0.148 & $(0.843)$ & 0.894 & $(0.670)$ \\
\hline Urban & -0.023 & $(0.025)$ & -0.038 & $(0.022)$ & -0.051 & $(0.027)$ & -0.018 & $(0.030)$ & -0.057 & $(0.022)$ & -0.019 & $(0.026)$ & -0.001 & $(0.030)$ & -0.043 & $(0.022)$ \\
\hline Rented & -0.029 & $(0.132)$ & -0.012 & $(0.059)$ & 0.179 & $(0.097)$ & -0.003 & $(0.337)$ & -0.145 & $(0.092)$ & 0.044 & $(0.120)$ & 0.092 & $(0.090)$ & -0.060 & $(0.115)$ \\
\hline SinglePa & -0.008 & $(0.171)$ & 0.198 & $(0.385)$ & -0.293 & $(0.452)$ & -0.716 & $(0.581)$ & -0.041 & $(0.251)$ & -0.288 & $(0.397)$ & 0.006 & $(0.122)$ & 0.131 & $(0.343)$ \\
\hline Age1819 & 0.383 & (1.529) & 2.094 & (1.205) & 3.006 & (1.537) & 1.458 & $(1.316)$ & 3.593 & (1.596) & 2.557 & (1.396) & 0.447 & (1.498) & -2.456 & (1.310) \\
\hline Age2029 & -0.050 & $(0.340)$ & -0.166 & $(0.390)$ & -0.201 & $(0.330)$ & -0.020 & $(0.628)$ & 0.138 & $(0.477)$ & -0.147 & $(0.287)$ & -0.063 & $(0.444)$ & 0.312 & $(0.299)$ \\
\hline UIOut & -0.283 & $(0.155)$ & 0.187 & $(0.131)$ & -0.165 & $(0.165)$ & -0.292 & $(0.257)$ & 0.108 & $(0.164)$ & -0.006 & $(0.175)$ & 0.248 & $(0.193)$ & -0.089 & $(0.152)$ \\
\hline UIOut-1 & 0.254 & $(0.151)$ & -0.263 & $(0.143)$ & 0.307 & $(0.124)$ & 0.222 & $(0.177)$ & -0.703 & $(0.212)$ & -0.158 & $(0.146)$ & 0.018 & $(0.260)$ & 0.346 & $(0.171)$ \\
\hline GDP-1 & 0.002 & $(0.003)$ & 0.005 & $(0.003)$ & 0.004 & $(0.002)$ & 0.001 & $(0.002)$ & -0.009 & $(0.003)$ & -0.002 & $(0.003)$ & -0.005 & $(0.002)$ & 0.000 & $(0.002)$ \\
\hline SA-1 & 27.465 & $(1.004)$ & 29.706 & $(1.480)$ & 34.059 & (1.269) & 35.658 & $(1.715)$ & 30.805 & $(1.336)$ & 25.052 & $(1.241)$ & 23.651 & $(2.143)$ & 28.355 & (1.397) \\
\hline Immigran & -0.698 & $(0.160)$ & -0.619 & $(0.145)$ & -0.466 & $(0.183)$ & -0.605 & $(0.145)$ & -0.745 & $(0.140)$ & -0.461 & $(0.158)$ & -0.609 & $(0.143)$ & -0.533 & $(0.140)$ \\
\hline LowSkill & 0.372 & $(0.153)$ & 0.191 & $(0.160)$ & 0.093 & $(0.147)$ & 0.100 & $(0.205)$ & -0.011 & $(0.145)$ & 0.295 & $(0.198)$ & 0.243 & $(0.145)$ & 0.552 & $(0.160)$ \\
\hline Disabled & -0.642 & $(0.379)$ & -0.458 & $(0.358)$ & -0.412 & $(0.379)$ & -0.304 & $(0.453)$ & -0.630 & $(0.405)$ & -0.240 & $(0.505)$ & -1.189 & $(0.484)$ & -1.154 & $(0.493)$ \\
\hline Urban & -0.031 & $(0.030)$ & -0.028 & $(0.021)$ & 0.002 & $(0.051)$ & 0.000 & $(0.051)$ & -0.008 & $(0.019)$ & -0.026 & $(0.022)$ & -0.006 & $(0.033)$ & -0.011 & $(0.021)$ \\
\hline Rented & -0.018 & $(0.164)$ & -0.059 & $(0.126)$ & -0.012 & $(0.146)$ & -0.100 & $(0.102)$ & -0.102 & $(0.102)$ & -0.070 & $(0.092)$ & -0.064 & $(0.097)$ & -0.163 & $(0.112)$ \\
\hline SinglePa & -0.339 & $(0.376)$ & -0.476 & $(0.374)$ & -0.817 & $(0.350)$ & -1.190 & $(0.403)$ & -0.594 & $(0.330)$ & -0.715 & $(0.368)$ & -0.513 & $(0.341)$ & -0.271 & $(0.339)$ \\
\hline Age1819 & 0.298 & $(1.242)$ & 0.040 & $(0.583)$ & 0.293 & (1.295) & -1.034 & (1.467) & 0.070 & (1.115) & -0.508 & (1.497) & 0.028 & $(0.148)$ & -0.281 & $(0.813)$ \\
\hline Age2029 & -0.807 & $(0.273)$ & -0.980 & $(0.213)$ & -0.713 & $(0.223)$ & -0.203 & $(0.317)$ & -0.429 & $(0.311)$ & -0.373 & $(0.254)$ & -0.829 & $(0.201)$ & -0.419 & $(0.214)$ \\
\hline UIOut & -0.204 & $(0.143)$ & 0.162 & $(0.107)$ & -0.141 & $(0.128)$ & -0.277 & $(0.353)$ & 0.053 & $(0.133)$ & -0.132 & $(0.153)$ & -0.013 & $(0.358)$ & 0.022 & $(0.147)$ \\
\hline UIOut-1 & 0.151 & $(0.138)$ & -0.246 & $(0.109)$ & 0.135 & $(0.097)$ & 0.046 & (0.289) & -0.385 & $(0.171)$ & -0.210 & $(0.133)$ & -0.083 & $(0.512)$ & -0.230 & $(0.156)$ \\
\hline GDP-1 & -0.001 & $(0.003)$ & -0.002 & $(0.002)$ & 0.003 & $(0.002)$ & -0.001 & $(0.004)$ & -0.006 & $(0.002)$ & -0.001 & $(0.003)$ & -0.002 & $(0.002)$ & -0.003 & $(0.003)$ \\
\hline SA-1 & 38.899 & $(1.016)$ & 37.845 & $(1.073)$ & 35.898 & (1.064) & 38.903 & (1.061) & 38.624 & $(0.992)$ & 41.128 & (1.085) & 42.413 & $(1.030)$ & 42.118 & (1.159) \\
\hline Immigran & -0.129 & $(0.045)$ & -0.134 & $(0.041)$ & -0.140 & $(0.034)$ & -0.158 & $(0.039)$ & -0.066 & $(0.049)$ & -0.082 & $(0.054)$ & -0.188 & $(0.053)$ & -0.223 & $(0.053)$ \\
\hline LowSkill & 0.013 & $(0.045)$ & 0.037 & $(0.051)$ & -0.034 & $(0.041)$ & -0.022 & $(0.044)$ & -0.048 & $(0.054)$ & 0.047 & $(0.052)$ & 0.084 & $(0.057)$ & 0.065 & $(0.064)$ \\
\hline Disabled & 0.493 & $(0.110)$ & 0.331 & $(0.105)$ & 0.507 & $(0.114)$ & 0.606 & $(0.117)$ & 0.529 & $(0.135)$ & 1.042 & $(0.156)$ & 1.015 & $(0.178)$ & 1.372 & $(0.205)$ \\
\hline Urban & -0.011 & $(0.006)$ & -0.004 & $(0.006)$ & 0.002 & $(0.006)$ & 0.001 & $(0.006)$ & 0.010 & $(0.006)$ & 0.000 & $(0.011)$ & 0.023 & $(0.008)$ & 0.020 & $(0.008)$ \\
\hline Rented & 0.010 & $(0.026)$ & -0.007 & $(0.024)$ & -0.060 & $(0.025)$ & -0.008 & (0.033) & -0.004 & $(0.023)$ & 0.020 & $(0.030)$ & 0.051 & $(0.039)$ & -0.010 & $(0.044)$ \\
\hline SinglePa & 0.038 & $(0.136)$ & 0.144 & $(0.086)$ & -0.010 & $(0.040)$ & 0.039 & $(0.100)$ & -0.204 & $(0.097)$ & -0.255 & $(0.124)$ & -0.205 & $(0.121)$ & -0.172 & $(0.131)$ \\
\hline Age1819 & 1.133 & $(0.368)$ & 0.987 & $(0.338)$ & 1.078 & $(0.339)$ & 1.285 & $(0.357)$ & 0.225 & $(0.440)$ & 1.108 & $(0.440)$ & 1.814 & $(0.502)$ & 1.063 & $(0.480)$ \\
\hline Age2029 & -0.107 & $(0.073)$ & -0.079 & $(0.071)$ & 0.040 & $(0.082)$ & -0.008 & (0.069) & 0.040 & $(0.076)$ & 0.008 & $(0.096)$ & -0.095 & $(0.104)$ & 0.188 & $(0.091)$ \\
\hline UIOut & -0.042 & $(0.039)$ & 0.036 & $(0.031)$ & -0.029 & $(0.046)$ & 0.093 & (0.058) & 0.095 & $(0.046)$ & -0.029 & $(0.053)$ & -0.001 & $(0.013)$ & 0.005 & $(0.037)$ \\
\hline UIOut-1 & 0.033 & $(0.038)$ & -0.019 & $(0.030)$ & 0.010 & $(0.036)$ & 0.017 & $(0.042)$ & 0.084 & $(0.061)$ & 0.161 & $(0.045)$ & -0.027 & $(0.099)$ & -0.026 & $(0.066)$ \\
\hline GDP-1 & -0.001 & $(0.001)$ & 0.000 & $(0.001)$ & 0.000 & $(0.001)$ & 0.000 & $(0.001)$ & 0.002 & $(0.001)$ & -0.001 & $(0.001)$ & 0.001 & $(0.001)$ & -0.002 & $(0.001)$ \\
\hline SA-1 & 1.177 & $(0.322)$ & 1.087 & $(0.283)$ & 1.636 & $(0.262)$ & 1.429 & $(0.288)$ & 1.857 & $(0.278)$ & 2.344 & $(0.349)$ & 3.298 & $(0.378)$ & 3.346 & $(0.464)$ \\
\hline C_S & 0.019 & $(0.088)$ & -0.095 & $(0.151)$ & -0.189 & $(0.082)$ & 0.048 & $(0.126)$ & 0.279 & $(0.136)$ & -0.025 & $(0.159)$ & -0.235 & $(0.180)$ & -0.201 & $(0.144)$ \\
\hline C_F & 0.208 & $(0.093)$ & 0.288 & $(0.097)$ & 0.193 & $(0.087)$ & 0.372 & $(0.095)$ & 0.415 & $(0.090)$ & 0.388 & $(0.131)$ & 0.284 & $(0.124)$ & 0.273 & $(0.117)$ \\
\hline C_D & 0.003 & $(0.033)$ & -0.018 & $(0.032)$ & 0.019 & $(0.025)$ & -0.066 & $(0.027)$ & -0.050 & $(0.034)$ & -0.075 & $(0.044)$ & -0.020 & $(0.070)$ & -0.003 & $(0.062)$ \\
\hline V_SF & 0.407 & $(0.047)$ & 0.302 & $(0.042)$ & 0.351 & $(0.047)$ & 0.343 & $(0.048)$ & 0.161 & $(0.038)$ & 0.337 & $(0.049)$ & 0.103 & $(0.031)$ & 0.225 & $(0.041)$ \\
\hline V_SD & 0.006 & $(0.011)$ & 0.001 & $(0.009)$ & 0.012 & $(0.012)$ & 0.012 & $(0.011)$ & 0.005 & $(0.011)$ & 0.019 & $(0.004)$ & 0.015 & $(0.015)$ & 0.005 & $(0.010)$ \\
\hline V_FD & 0.004 & $(0.010)$ & -0.006 & $(0.008)$ & 0.011 & $(0.009)$ & 0.018 & $(0.009)$ & 0.003 & $(0.010)$ & 0.039 & $(0.008)$ & 0.037 & $(0.013)$ & 0.009 & $(0.011)$ \\
\hline V_S & 0.779 & $(0.066)$ & 0.784 & $(0.066)$ & 0.914 & $(0.076)$ & 0.910 & $(0.083)$ & 0.791 & $(0.067)$ & 0.927 & $(0.075)$ & 0.525 & $(0.051)$ & 0.792 & $(0.067)$ \\
\hline V_F & 0.651 & $(0.056)$ & 0.574 & $(0.048)$ & 0.610 & $(0.052)$ & 0.651 & $(0.054)$ & 0.581 & $(0.049)$ & 0.776 & $(0.061)$ & 0.582 & $(0.051)$ & 0.573 & $(0.049)$ \\
\hline V_D & 0.049 & $(0.004)$ & 0.041 & $(0.004)$ & 0.049 & $(0.004)$ & 0.047 & $(0.004)$ & 0.060 & $(0.005)$ & 0.078 & $(0.006)$ & 0.093 & $(0.008)$ & 0.102 & $(0.008)$ \\
\hline RAN_S & 0.389 & $(0.009)$ & & & & & & & & & & & & & & \\
\hline RAN_F & 0.287 & $(0.006)$ & & & & & & & & & & & & & & \\
\hline RAN_D & 0.032 & $(0.001)$ & & & & & & & & & & & & & & \\
\hline RHO_S & 0.052 & $(0.011)$ & & & & & & & & & & & & & & \\
\hline RHO_F & 0.131 & $(0.011)$ & & & & & & & & & & & & & & \\
\hline RHO_D & 0.039 & $(0.011)$ & & & & & & & & & & & & & & \\
\hline
\end{tabular}


Publisher:

CPB Netherlands Bureau for Economic Policy Analysis

P.O. Box $80510 \mid 2508$ GM The Hague

$\mathrm{T}(070) 3383380$

July 2011 | ISBN 978-90-5833-519-7 